San Jose State University

SJSU ScholarWorks

Master's Theses

Master's Theses and Graduate Research

Spring 2012

\title{
The Role of Language in Shaping the International Cultural Tourism Experience of Student-travelers
}

Avina Ramnani

San Jose State University

Follow this and additional works at: https://scholarworks.sjsu.edu/etd_theses

Part of the Tourism Commons

\section{Recommended Citation}

Ramnani, Avina, "The Role of Language in Shaping the International Cultural Tourism Experience of Student-travelers" (2012). Master's Theses. 4163.

DOI: https://doi.org/10.31979/etd.g3jh-gkqr

https://scholarworks.sjsu.edu/etd_theses/4163

This Thesis is brought to you for free and open access by the Master's Theses and Graduate Research at SJSU ScholarWorks. It has been accepted for inclusion in Master's Theses by an authorized administrator of SJSU ScholarWorks. For more information, please contact scholarworks@sjsu.edu. 
THE ROLE OF LANGUAGE IN SHAPING THE INTERNATIONAL CULTURAL TOURISM EXPERIENCE OF STUDENT-TRAVELERS

\begin{abstract}
A Thesis
Presented to

The Faculty of the Department of Hospitality, Recreation \& Tourism Management San Jose State University

In Partial Fulfillment

of the Requirements for the Degree

Master of Science

by

Avina Ramnani
\end{abstract}

May 2012 
(C) 2012

Avina Ramnani

ALL RIGHTS RESERVED 
The Designated Thesis Committee Approves the Thesis Titled

\title{
THE ROLE OF LANGUAGE IN SHAPING THE INTERNATIONAL CULTURAL TOURISM EXPERIENCE OF STUDENT-TRAVELERS
}

by

Avina Ramnani

\begin{abstract}
APPROVED FOR THE DEPARTMENT OF
HOSPITALITY, RECREATION, AND TOURISM MANAGEMENT
\end{abstract}

SAN JOSE STATE UNIVERSITY

May 2012

Dr. Randy J. Virden

Dr. Theodore Butryn

Dr. Tsu-Hong Yen
Department of Hospitality, Recreation, and Tourism Management

Department of Kinesiology

Department of Hospitality, Recreation, and Tourism Management 


\title{
ABSTRACT \\ THE ROLE OF LANGUAGE IN SHAPING THE INTERNATIONAL CULTURAL TOURISM EXPERIENCE OF STUDENT-TRAVELERS
}

\author{
by
}

\section{Avina Ramnani}

This qualitative, exploratory study sought insight into how language affects the cultural tourism experience in the international tourism context. Data were obtained through semi-structured interviews of 13 student-travelers, who traveled with the San Jose State University's study-abroad programs. The analysis of the data was carried out within a socio-linguistic context using grounded theory methods. Findings indicated that travel motivations and the perception of significance of the language spoken at a destination were intimately connected. Further, the desire on the part of the studenttravelers to experience the local culture affected the desire for interaction with the host population, which was in turn affected by the language skills of the tourists as well as the host population. Tourism experience was negatively or positively affected by the level of fluency of the student-travelers in the local language, which was affected by the place that the local language held within their initial travel motivations. Fluency in the local language was regarded as a facilitator of positive experiences, whereas lack of knowledge of the local language created a language barrier that inhibited positive experiences. Length of stay, which was a crucial common factor between all student-travelers, was an overarching factor that influenced the role that language played in the shaping of the tourism experiences of these student-travelers. 


\section{ACKNOWLEDGMENTS}

This thesis was made possible by the constant support and encouragement of many individuals. Foremost is Dr. Randy Virden, whose guidance was of utmost importance to the conception and execution of this research. With his tremendous help during the entire research process, I was able to find my research focus and stick to it. Dr. Theodore Butryn, I am immensely grateful for your generosity as well as patience. The opportunity to attend your class helped me understand the qualitative process better, and provided the much needed insight that I lacked when I had started this research study. Dr. Tsu-Hong Yen, I am very grateful for your timely support and constant encouragement, along with your greatly helpful feedback and suggestions pertaining to this study.

I would also like to express sincere and heartfelt thanks to the amazing studenttravelers who participated in this study. Your readiness to share your experiences, and your insight as well as the ability to articulate those experiences is truly inspiring.

Thanks to my husband, who was extremely encouraging throughout the research process, and supportive of my own desire to travel abroad and participate in the study abroad program: the experience that led me to this research study in the first place! Thanks also to my wonderful parents, my two sisters, and my friends whose unrelenting support has always given me the confidence to keep pushing my limits! 


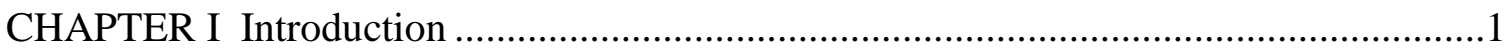

Problem Statement and Background ...............................................................5

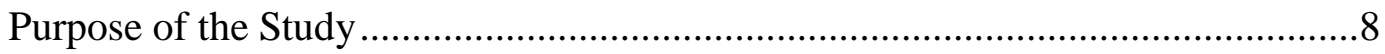

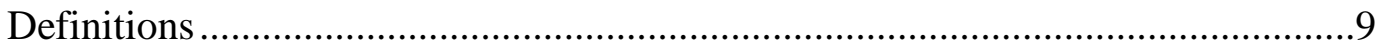

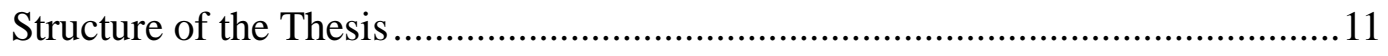

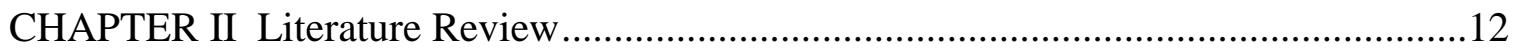

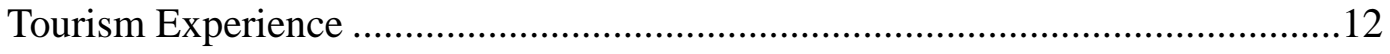

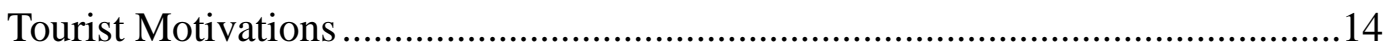

Tourist Motivations and Tourist Typologies ...................................................16

Tourist Motivations and Student-travelers ………………..............................19

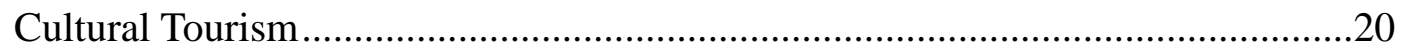

Cultural Tourism and Authenticity ..............................................................22

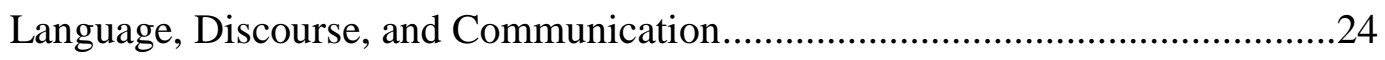

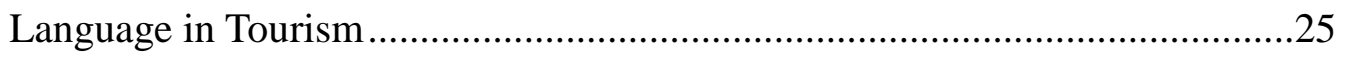

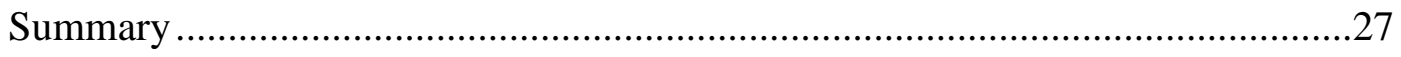

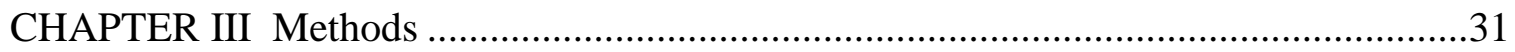




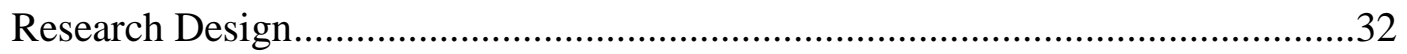

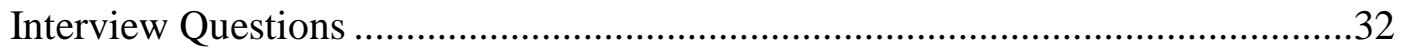

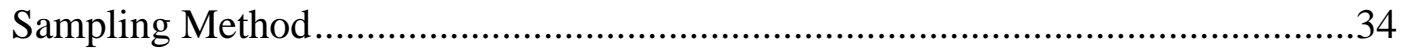

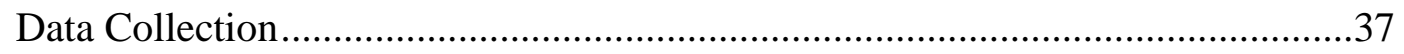

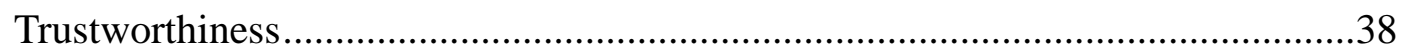

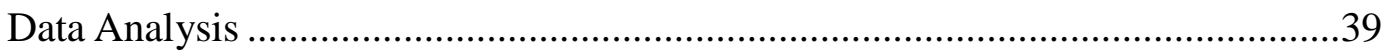

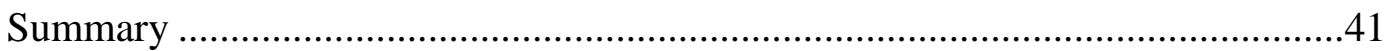

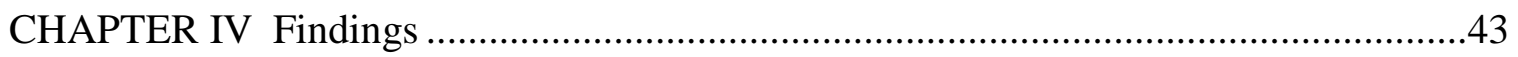

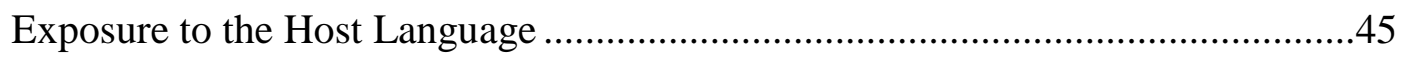

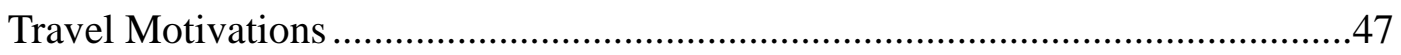

Escape from Boredom................................................................................ 48

Experiencing a New Country .............................................................................48

Learning another Country's Language through Immersion in Culture................51

Desire to Learn about a Different Culture ……………………………….......54

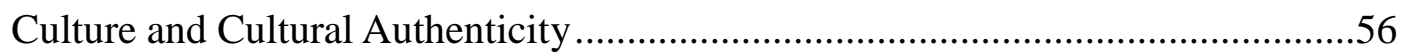

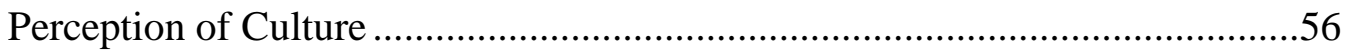

Staying with a Local Family ...........................................................................5

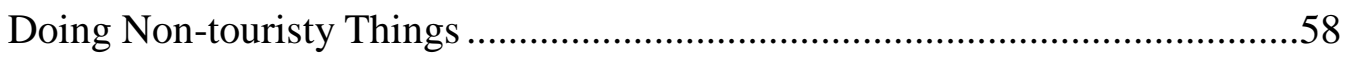

Interacting with the Locals in their Own Language..........................................61 
Living like a Local

Perception of Significance of the Language and Interaction with the Hosts

Preparation

Challenges

Perception of Significance of Interaction with the Host Population.

Language as a Facilitator of the Tourism Experience.

Opportunity for Immersion in Culture.

Positive Experiences with the Locals

Bonding with Students over the Host Language

Attachment to the Place

Active Language Barrier Negotiation

Length of Stay

Non-verbal Cues

Feeling of Accomplishment .....

Ability to Actively Interact with the Locals.

Language as an Inhibitor of the Desired Travel Experience

Culture Shock and Adjusting .....

Negative Experiences with the Hosts

Interest of Locals, and Local or International Students, in Learning 
English..

Confinement to Touristic Activities, Bigger Cities, or Larger Groups.. ......87

Summary

CHAPTER V Discussion and Conclusion

Question One: What Travel Motivations Drive the Subjects?....

Question Two: What are the Different Ways to Talk about "Cultural

Authenticity"?

Language and Discourse

Living like a Local

Question Three: How Significant is Language and Interaction with the

Locals?

Question Four: How Language Shapes the Tourism Experience?.......

Limitations

Conclusions

Recommendations 110

Areas for Future Research

REFERENCES

APPENDIX A Interview Questions

APPENDIX B Informed Consent Form 
APPENDIX C Human Subjects-Institutional Review Board Approval Letter..........122

\section{LIST OF TABLES}

Table 1

Motivation to travel, place of travel and the host language .........................................44

Table 2

Exposure to host country's language, place of travel and the host language....................46 


\section{LIST OF FIGURES}

Figure 1

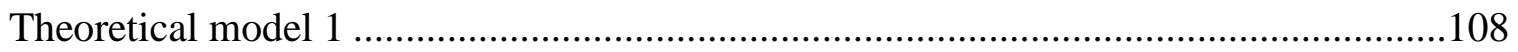

Figure 2

Theoretical model 2

109 


\section{Chapter One}

\section{Introduction}

International tourism is almost a two trillion dollar global industry that has grown exponentially over the past few decades. Owing to the many differences in culture between different places, travel to different countries in the world is replete with the opportunity for an intensely multilingual and intercultural experience (Phipps, 2006), presumably leading to a very rich discourse between tourists and locals. Tourism sociologists, social geographers, and cultural theorists have, in recent years, become interested in the cultures and activities of adventure travelers and independent travelers in the international tourism domain (Jaworski \& Pritchard, 2005). This trend is symbolic of the importance of international travel in the fields of social and cultural studies as well as to some extent in the field of linguistics and communication. Conversely, it is now seen that discourse and communication, which are directly linked to language, are beginning to attract tourism scholars (Phipps, 2006). Jaworski and Prichard (2005) aptly define communication as

"The practices, processes, and mediums by which meanings are produced and understood in a cultural context and could include almost anything- from a wave of the hand to the system of interconnected computers that constitute the internet (p. 2)."

Given this definition, communication purportedly assumes a fundamental and basic concern of disciplines across the humanities and social sciences. Communication can easily be seen as an important tool necessary for the propagation of culture as well as assuming a central role in tourism and tourist discourse. Jaworski and Pritchard (2005) call discourse and communication "the vital prisms" through which tourism can be 
examined. This study used discourse and communication, the vital elements of language and culture, as the context within which to explore and understand the tourism experience. The premise of this study was that tourism motivations define expectations from the travel, which in turn drive tourist behavior. The aim was to explore how these expectations affected behavioral factors and the tourism discourse, and how these interact with the behavioral and cultural factors of the host society to finally shape the experience of the tourists. The argument was that the domain of tourism, and of tourism experience, is replete with complex factors that work in two directions. Thus, even though the tourist might go in with expectations that would drive behavior, the hosts and their societal norms interfere with the expected tourism discourse, most likely affecting the fulfillment of these expectations, and finally decide the outcome of the travel.

The strategy to delve into these experiences thus involved the exploration of tourism communication or tourism discourse experiences of tourists. Pearce and Stringer (1991) emphasize that tourism is "essentially a social psychological phenomenon". Thus, an assumption can be made that the commonality of the lived experiences of tourists, as it relates to a given context and set of conditions, can be understood and explored better through research that takes into account the social and psychological factors involved in shaping tourist experiences. Additionally, tourism planners are best advised to study tourist behavior in psychological terms (Gnoth, 1997). So far, the only extensive research on tourism planning has been on the intercultural training of tourists to maximize customer experience, and it has been largely quantitative (Leclerc \& Martin, 2004). However, social identities, tourist learning, and engagement of tourists with the 
locals are all essential factors in tourism discourse and affect the tourist experience. Since these factors have been neglected in tourism research so far, it presents a ripe opportunity to study the effect of these factors on tourism experience. This opportunity forms a sound basis for qualitative, specifically, phenomenological inquiry. It is felt that by hearing the stories of tourists in a given setting, it is possible to find common underlying themes in these descriptions of experiences that could help understand the essence of such an experience in the given context. For this study, the context is that of tourism discourse and communication and interaction with the hosts.

Tourism is inherently driven by the motivation to travel, and tourism experience reflects stable patterns of motivations noticeable through various modes of tourists' activities (Cohen, 1979). A discussion on various motivations behind traveling is essential to contextualize the topic of this study. The motivations to travel represent patterned ways of satisfying a wide range of personal needs, from pleasure to the search for meaning ( $\mathrm{Li}, 2000)$. A general definition of tourism may be drawn from the different studies following Cohen's (1979) proposed theory regarding types of tourists. Tourism can be regarded as a multifunctional leisure activity that involves either entertainment or learning, or both, for an individual (Ryan, 1997). Usually the learning mentioned here is a natural process occurring mostly incidentally (Kalinowski, 1992) and experientially in an individual's spatial interaction with the destination, taking place in the individual's geographical consciousness (Li, 2000). Generally speaking, geographical consciousness involves the experiences of spaces, places, and landscapes, both pleasant and unpleasant, that people have in the process of traveling (Billinge, 1977; Buttimer, 1976; Seamon, 
1979; Tuan, 1977, 1989, 1993). Drawing a parallel with this line of reasoning, it may be proposed that while traveling, people also undergo learning or meaning-making, whether consciously or not, through their encounters with different languages and through their interactions with the hosts. These experiences take place in their linguistic consciousness, which consists of indirect expressions of language attitudes, explicit comments in interactions, and observed as well as reported use of the languages (Woolard, 1998).

The experience of tourism can be understood by using the different travel motivations of learning, nostalgia, explorations, feeling of independence, means of socializing, and so on, as the basic platform from which to build the understanding. These experiences happen in one's linguistic consciousness also, as mentioned above, apart from being planned and sought, and thus happen naturally and incidentally (Kalinowski, 1992). It is this experiential domain, that might involve different sorts of learning (albeit not consciously, and is essentially unforced) through interactions with people at culturally different locations, that forms the basis of the author's research. The assumption is that there must be many facets of tourist experiences that occur through linguistic consciousness, and the aim is to explore and understand them.

The field of phenomenology takes into account the conscious, meaningful experiences of an individual based on the belief that the reality of a phenomenon being studied can only be perceived within the meanings of the experiences of the individual (Creswell, 2007). It can thus be proposed that the conscious experiences of several tourists in the context of international cultural tourism represent a phenomenon that can be studied to understand how these individuals commonly view the phenomenon. 
Further, the focus is the toured place's native or spoken language as an important symbol of authenticity in the context of these experiences. The aim is to describe and understand the essence of these tourist experiences in terms of the difference between the local language and that of the tourists. As mentioned before, this topic lends itself well to phenomenological inquiry as anything that appears to consciousness is a legitimate area of phenomenological investigation ( $\mathrm{Li}, 2000)$. Quantitative methods are not suited to investigate the underlying dimensions and structures of the human experience, which are necessary to understand it at a deeper level, and produce clear, precise and systematic descriptions of the meaning constituting the experience. The goal of this study is to describe, not explain, the phenomenon of significance of language in the context of international cultural tourism experience.

\section{Problem Statement and Background}

Tourism is a massive multilingual phenomenon (Phipps, 2006), potentially untouched by research that addresses the interplay of language and patterns of touristhost interactions. Despite the obviously central importance of conversation and communication in tourism studies, these areas have stayed relatively unexplored and under-theorized among tourism researchers. Even when specific links between tourism and language were made, the "vast tradition of discourse (p. 2)" was ignored for the most part, and remained non-empirical (Jaworski \& Pritchard, 2005). In a similar vein, modern linguists tend to ignore tourism in their research (Phipps, 2006). Sociolinguistics and discourse analysis, that primarily deal with discourse and communication, have only fairly recently recognized the domain of international tourism as a relevant area of study. 
Thus, there is a very ripe opportunity to delve into this previously uncharted territory, which is only now beginning to be explored, and explore and theorize the complex and multifaceted relationships (Jaworski \& Pritchard, 2005) between language and tourism.

The study presupposes that this opportunity would allow the researcher to access and understand the underlying behavioral and cultural factors that govern the communication between locals of the toured place and the tourists, and how they shape the tourism experience. This study seeks to fill the gap in research addressing the interplay of language and tourism experiences by examining the various dimensions of the experiences of tourists. In doing so, the main focus would be on the effect that the difference in the spoken or native language of the tourists and the hosts has on the international (cultural) tourism experience.

This knowledge is significant for many reasons. First, language is an intricate part of the culture of a place and is inseparable from it. To experience a place's culture authentically needs an acknowledgment of the differences in different cultures of the world, including their language. Second, in spite of recognizing the relation of language to cultural tourism, researchers have not yet studied the role that language plays in meeting the expectations of the tourists, and thus shaping the tourism experience and influencing tourist satisfaction. There thus exists a big void in the research in this area, although a few studies (Bonn, Joseph \& Dai, 2010; Kennett, 2002) have touched upon this subject. In particular, they have tried to research how destination choice gets affected by the difference in languages of places. For instance, mass tourists for the most part were seen to choose destinations where their native language was spoken, and avoid 
locations where they did not find this convenience (Bonn, Joseph \& Dai, 2010; Kennett, 2002). Third, the knowledge of how the phenomenon of language and its variability affects tourism experience is important to provide insights for further research. This knowledge can also be used by tourism planners and managers to address problems involving tourist satisfaction.

To be able to understand the role that language plays in shaping tourist experiences, it was felt that these experiences must be recounted by the tourists to enable an insight into the tourist psyche and perception. In other words, through active narrative productions by the tourists themselves (Elliot, 2005), their stories would guide the exploration of the importance, or conversely the insignificance of the difference between the host and the tourist language as it relates to tourist experiences.

These narratives were produced during an in-depth interview (narrative ethnographic methodology) where questions were designed to help the research participants adopt a position of narration and story-telling. The sample consisted of students from San Jose State University who had spent 1 month or more, and up to a year, in a foreign setting with a difference in the spoken language (in other terms, where English is not the local spoken language). These students traveled abroad as part of an official "SJSU Study Abroad Program". The rationale for this sample was that these students are also travelers, and they are from the United States where English is the primarily spoken language. The assumption was that they would all be at different levels of proficiency with the spoken language and some would not know the language at all when they started their Study Abroad program. This was ideal for this study as it 
presented an opportunity for collecting richer data owing to the subtle differences in the participants making up the sample and experiencing the same phenomenon.

\section{Purpose of Study}

The purpose of this study is to examine the underlying cultural and behavioral factors pertaining to the role that the host language plays in the tourist experience. The spoken language here refers to the language spoken by hosts (both residents and service providers) and by the tourists. It is felt that the difference between the spoken language of the tourists and that of the hosts deserves much more attention than it has received so far in research. Since language is an integral component of the tourism experience, especially of international cultural tourism, the difference between tourist and host language is also an important determinant of the tourism experience. Based on this felt need to explore the role that language plays in shaping the tourism experience in the international context, the following guiding questions were developed for this research study:

- What travel motivations drive the subjects to decide in favor of traveling to the particular destination that they travel to?

- What are the different ways in which the tourists talk about 'cultural authenticity'?

- What are some of the ways in which these experiences are shaped by the difference in the language spoken at the destination and the native language of the tourists?

- What significance do the student travelers assign to the interaction with the locals and the role of language in regards to their tourism experiences?

The important concepts highlighted in the research would be: travel motivations, 
student-travelers' expectations from their tourism experience, student-traveler satisfaction, tourism experience, and the place and role of language and interactions with the hosts in defining this experience.

\section{Definitions}

Tourism. Tourism is defined as travel for recreational or leisure purposes. A tourist can be defined as 'a temporary, voluntary traveler on a long journey, travelling for the experience of novelty and change brought about by a non-recurrent round trip' (Cohen, 2004).

Cultural tourism. Tourism involving consumption of the way of life (contemporary culture) of places visited, in addition to visiting sites and monuments that could be described as the cultural products (Timothy \& Boyd, 2003). It is also a genre of special interest tourism based on the search for and participation in new and deep cultural experiences, whether aesthetic, intellectual, emotional, or psychological (Reisinger 1994:24).

Authenticity. The notion of continuity in a toured place, and of proof of the past, in that the sources, forms, style, language and symbol (of a people) all derive from a supposedly homogeneous and unbroken tradition (Taylor, 2001).

Constructive Authenticity. Constructive authenticity deals with the symbols of authenticity, and it is an assumption made in the research that one of the symbols of the authenticity is the native/spoken language of the toured place. This form of authenticity forms the basis for the focus of this study, that is, 'language' and its role in international tourism (Wang, 1999). 
Existential Authenticity. Existential authenticity is a subset of constructive authenticity that involves personal or inter-subjective feelings activated by the liminal process of tourist activities, in which people consider themselves more authentic and more freely expressed than in everyday life since they are engaging in non-ordinary activities free from the routine of their daily lives (Wang, 1999).

Language. The communication of thoughts and feelings through a system of arbitrary signals, such as voice sounds, gestures, or written symbols (www.askoxford.com).

Linguistic consciousness. The consciousness of the spoken word or the experience of the world through linguistic interactions, which is expressed by indirect expressions of language attitudes, explicit comments in interactions, and observed as well as reported use of the languages (Woolard, 1998 ).

Narrative methodology. The methodology suitable for a phenomenological study would be narrative ethnographic methodology that focuses on how people perceive experiences, and on the meanings they make of the experiences, evident in the process of recounting them; and not why they perceive what they perceive during their experiences in the world (Elliott, 2005).

Phenomenology. The discipline that studies the structures of experience, or consciousness. Literally, phenomenology is the study of "phenomena": appearances of things, or things as they appear in our experience, or the ways we experience things, thus the meanings things have in our experience. It involves describing as well as interpreting the meaning of lived experiences of people (Creswell, 2007). 
Transcendental or Psychological Phenomenology. Proposed by Moustakas (1994), transcendental or psychological phenomenology focuses primarily on the description of the experiences of the participants. This methodology utilizes the technique of bracketing (called epoche) through which researchers put aside their experiences in order to undertake a fresh perspective toward the description of the phenomenon under examination (Creswell, 2007).

\section{Structure of the Thesis}

The rationale for conducting the research for this thesis is explained in Chapter I, which introduces the topic of the thesis, its purpose, the significance or the felt need for studying the topic and the problem statement that needs to be addressed through the thesis. It also includes some questions that will guide the research. Chapter II contains an extensive literature review in the areas that are intricately related to the topic of study, and mentions previous research upon which certain assumptions of the study have been based. Chapter III contains description of the research method, the rationale behind employing qualitative means to collect and analyze data, and means to ensure trustworthiness and credibility. Chapter IV lists the various findings of the research, based on the data collected during participant interviews and an analysis of student blogs and online journals. Chapter V covers a discussion of the findings of the research, and the conclusions drawn by the researcher based on these findings in relation to the study at hand. 


\section{Chapter Two}

\section{Literature Review}

This chapter summarizes key points related to the study, after a review of the literature available in scholarly journals and seminal works on travel motivations, tourist typologies, cultural tourism, authenticity, the importance of language and discourse with respect to culture, and tourism experience. After touching upon cultural tourism and authenticity, the literature review is aimed to highlight the research gap in terms of the study of language in relation to the discipline of tourism. This is true especially with respect to tourism experience, and there is a need to addresses this gap because of the significant link between discourse and tourism.

\section{Tourism Experience}

Tourism represents significant psychological, social, and economic differences from other, similar behavior during which people leave and return to their home (Gnoth, 1997). Tourists' felt needs drive their tourism motivations, and shape the final outcome of their travel, which is essentially their perception of their experience as tourists (Gnoth, 1997).

Tourist experience has been a key research topic since its early days during the 1960s (Uriely, 2005). It focuses on the cumulative travel experience (Oppermann, 1995), which is affected by the initial motivations to travel as well as other unforeseeable factors that the tourists encounter during their visit to a destination. The interest so far, however, has been more on the existential dimension of tourists' valuations of their personal experiences, and has been focused on tourism motivations and the meanings that tourists 
assign to their experiences in contrast to their everyday life. In his study, Uriely (2005) identified four important developments in tourism studies that address the distinctiveness of tourism from everyday life experience. These include a shift from homogenizing depictions of tourists to pluralizing representations that capture the multiplicity of the tourism experience; a shift from objectivity to the subjective negotiation of meanings as a determinant of the experience, and a movement from absolute truths toward relative and complementary interpretations. These developments also support Cohen's (1979) claims that not all tourists travel for the same motivations; people seek different kinds of travel experiences reflected in some stable motivation patterns of the individuals, both differentiating as well as characterizing their activities (Li, 2000).

Researchers and scholars have proposed that all travelers have a natural tendency to identify their own experiences as unique and authentic (McCabe, 2005). McCabe and Stokoe (2004) (cited by McCabe, 2005) support that tourists tend to construct their experiences in relation to, contrasting with, or in distinction to those of others. However, this feature is evident, and can be explored in depth, only when the tourists are asked for an account of their behavior (McCabe, 2005), for example, if they are phenomenologically interviewed.

Basala and Klenosky (2001) also researched different factors affecting the degree of social and cultural interaction that the tourist indulges in at the host destination. According to this study, the tourist's fluency or lack thereof with the host destination's spoken language could constitute an important barrier in their travel decision and/or travel preparation, the level of interaction with the host, and the overall quality of their 
experience. In their study, however, the authors touch upon the effect of language on travel decision alone, suggesting that seekers of familiarity might be less tolerant to language differences than seekers of novel travel experiences. However, there still remains a huge gap in research on how language affects the tourism experience after travel decisions have been made, and travel has happened.

Research on the role that language differences play in shaping the experiences of tourists (especially cultural) is still very limited (Cohen \& Cooper, 1985; Basala \& Klenosky, 2001). Furthermore, there is a huge research gap on how these differences affect the tourists' interactions with the hosts, and in turn their experience of the culture of a place, and the level of authenticity experienced if the host country's/destination's personnel is well-versed in the tourists' language (Salazar, 2006). It is this study's aim to explore how fluency in a destination's language or the urge to learn it can drive the travelers to travel to certain destinations, and how it further influences their behaviors, learning, and in turn, their tourism experiences. Since tourists possess their motivations prior to their experiences (Dunn Ross \& Iso-Ahola, 1991), tourism experience is intrinsically related to, and originates with, tourist motivations.

\section{Tourist Motivations}

Various researchers have defined tourist motivations and tourist expectations in differing ways. Generally, motivations govern a person's choice of a certain behavior, under a given set of circumstances, for its expected results (Kozak, 2002). They contain results of situation-person interactions, and are cognitive in nature. Existing research on travel motivations has covered a broad array of study areas, such as sociology of travel 
motivation and how it stimulates tourist behavior, development of travel motivation measurements, travel motivations of different niche markets, different factors influencing tourist motivations etc (as cited by Hsu, Cai \& Li, 2010). Motivation, being a dynamic concept, tends to vary from one person to another (Kozak, 2002). Further, the wide range of human needs, difficulties in defining a set methodology for studying motivations, as well as cultural differences, make a widely agreed-on conceptual framework of tourist motivations (WTO, 1999) impossible to achieve (Hsu, Cai \& Li, 2010). Among the theories and models that have been developed to study tourist motivations empirically, the prominent ones propose the push-pull (Dann, 1977), allocentric-psychocentric (Plog, 1974), escape-seeking (Dunn Ross and Iso-Ahola, 1991), and travel career ladder models (Pearce\& Lee, 2005).

A variety of studies note that tourist motivations are multiple, meaning more than one motivation operates simultaneously (Crompton, 1979), and travel motives may change over time (Pearce, 1993). Travel may be undertaken to fulfill either physiological needs, such as food, climate, and health, or psychological ones, such as adventure and relaxation (Mayo \& Jarvis, 1981), or both. Studies on tourist motivations driven by the desire for particular kinds of experiences recognize different categories of tourists, and the heterogeneous nature of tourist motivations has been recognized by a few researchers by way of tourist typologies based on the relationship between personality and the tourism activity undertaken. 
Tourist motivations and tourist typologies. There has been a lot of research on the various types of tourism or tourists. Unraveling the differences in the types and forms of tourists has been a central theme in tourism studies (McCabe, 2005). Some of the various forms of tourism, based on the visible attributes and practices, such as visited destinations and attractions, length of the trip, types of accommodation, contact with locals etc. are, heritage or cultural tourism, dark tourism, leisure travel, visiting friends and relatives, educational tourism, eco-tourism etc. Types of tourists (or tourism) differ from these institutional forms of tourists (or tourism) (Uriely, 2002) in that they refer to the less tangible psychological attributes, such as tourists' attitudes with respect to the fundamental values of their own society, their motivations for travel, and the meanings they assign to their tourism experiences.

Some of the variables that are used to measure tourist motivations include 'to visit historical and cultural sites', 'to seek adventure', 'to relax', 'to get close to nature', 'to get away from home', and 'to be active' (Kozak, 2002). Although tourists themselves are not inclined to categorize themselves into fixed and well-defined typologies, academics and marketers alike find it more convenient to treat tourists as belonging to different categories in order to study and reach out to them in a more orderly fashion.

Cohen (1972) was the first to develop the idea of 'the sociology of international tourism', which was based on a fourfold typology of tourist experiences. Before this, tourists were treated as a largely homogenous group. According to Cohen $(1972,1979)$, tourists can be divided into four categories of mass tourists, individual mass tourists, explorers, and drifters. 
According to some researchers, travel is a means to "escape" the rigors of everyday life and routine temporarily. Much of the earlier research seemed to stress on escape through short vacations (Mannell \& Iso-Ahola, 1987). At the same time, some previous research has talked about the desire to experience novel destinations and cultures as a key motivator of travel behavior. The tourists, however, might seek these experiences in terms of varying degrees of familiarity or novelty sought (Basala \& Klenosky, 2001).

As described by various researchers, starting with Cohen (1972), mass tourism usually involves guided all-inclusive package tours with well-defined itineraries. When the need to travel is fulfilled via the path of most convenience, it is referred to as mass tourism, which also represents the consumption of tourism (Boorstin, 1964). The individual mass tourists prefer to stick to familiar settings and stay within their comfort zone as well. However, their itineraries are less structured when compared to those of mass tourists. The explorers and drifters seek novelty, are more adaptable and willing to step outside their comfort zones to interact closely with the host communities, attempt to get off the beaten path, and generally avoid tourist attractions. The explorers, however, like to plan their stay and transportation more rigorously than drifters (Basala \& Klenosky, 2001). Later on, Cohen proposed a fivefold phenomenological typology of tourist experience (Cohen, 1979), in which he defined a spectrum of experiences, at one end of which was the "recreational" mode where the tourists are attached to the center of their own society and travel is a form of recreation and escape. The quest for authenticity in such a form of tourism is limited. The other tourist modes are diversionary, 
experiential, and experimental. At the other extreme of this spectrum are the existential tourists who are deeply concerned with the authenticity of their experiences.

Yet other typologies were defined by Plog $(1974,1991 b)$, along a continuum from psycho-centric tourists, who are essentially seeking familiarity, to allo-centric, which refers to tourists seeking extreme adventure in their tourism experiences, with mid-centric ranges describing majority of the tourists. Another typology developed by Smith (1989) identifies seven types of tourists. This typology places tourists as charter tourists, with fixed itineraries and guided tours, at one extreme. At the other extreme are explorers, who are more like anthropologists living as active participant-observers, eating local food, and living the local lifestyle. Between these extremes lie the mass tourists, incipient mass tourists, unusual tourists, off-beat tourists, and elite tourists. Like the other two typologies, this typology can also be viewed along a travel-style continuum based on the level of familiarity or novelty sought when traveling (Basala and Klenosky, 2001).

Basala and Klenosky (2001) argue that tourists who seek familiarity, security or reduction of perceived risk when they travel are less likely to visit countries where they are unable to speak the local language, and concluded that fluency in the destination's language was a determinant of some people's choice to visit. This supports Cohen and Cooper's (1985) assertion that mass tourists will generally travel to destinations where their own language is also spoken (Canally \& Timothy, 2007). However, it can certainly be argued that Cohen's (1979) individual mass tourists, explorers and drifters, and Smith's (1989) unusual tourists, off-beat tourists, and explorers, are more likely to be open to the 
challenges of traveling to places where their own language is not spoken, and their experiences constitute the basis of this research. As mentioned before, these motivations could involve seeking either a pleasurable experience or the search for meaning (and/or learning), or may be both, since tourism a multifunctional leisure activity (Ryan, 1997).

Tourist motivations and student-travelers. In a study on foreign language versus second language learners, Dornyei (1990) reports that the primary reason language learners learn a second language is to travel. The author also enunciates the assimilative motivation to learn a second language that involves acquisition of language skills by exposure to the host environment. This supports Kennett's (2002) claim that language learners can be described as cultural tourists who have low visibility and are not part of a package tour but behave more like an individual mass tourist, or may be even an explorer, especially if they stay with a host family, ensconced in the language and culture of the hosts. However, whereas cultural differences between two different places may become a significant barrier in terms of interaction with the locals and adherence to customs and beliefs of the toured place, it may still carry a lot of appeal to students-travelers who travel with study abroad programs, and are searching for cultural authenticity.

For cultural tourists, authenticity of cultural heritage, experienced via cultural tourism, is a quintessential component of the majority of experiences sought, and this study will focus on language and its role in the context of international cultural tourism. Cultural tourism, which can be defined as consuming the way of life of places (contemporary culture) visited in addition to visiting sites and monuments that could be described as the cultural products (Timothy \& Boyd, 2003), is very closely linked to the 
concept of authenticity. Authenticity, in the most basic sense, relates to the search for the lost past and its features (MacCannell, 1973). The definition of authenticity itself, has, however, always been arguable (Fawcett \& Cormack, 2001; Selwyn, 1996). The exact nature of tourism authenticity is still not fully agreed upon (Selwyn, 1996), but there have been several efforts to define and categorize the concept of authenticity for ease of understanding, discussion and research (Bruner, 1991; Silver 1993), which will be discussed in the next section.

\section{Cultural Tourism}

Out of the different types of tourism, the focus of this study is cultural tourism in the international context. The growing popularity of this form of tourism is evidenced by WTO's recognition of the presence of heritage and culture as a component in 40 per cent of all international trips undertaken and cultural heritage is the quintessential component of many destination areas all over the world. Cultural tourism can more generally be defined as consuming the way of life of places visited, in other words the contemporary culture, in addition to visiting sites and monuments that could be described as the cultural products (Timothy \& Boyd, 2003). The culture of a place, according to Richards (2001a), comprises of processes like ideas and way of life of a particular people, and the outcomes of these processes, such as artifacts, buildings, arts, customs etc).

As Kenett (2002) puts it, cultural tourism has to do with the discovery of self in the eyes of the other, and accommodation (or not) of the diversity. In an article by Stebbins (1995), cultural tourism is defined as a genre of special interest tourism based on the search for and participation in new and deep cultural experiences, that could be 
aesthetic, intellectual, emotional, or psychological (Reisinger 1994:24).

According to Phipps (2006), languages are carriers of cultural legacies.

Furthermore, tourists, as carriers and makers of languages, are embedded in the process of cultural promotion. Evidently, there are powerful connections between languages and cultures, particularly in the domain of tourism.

When it comes to people who seek experiences, there is a segment of tourists who travel long enough, which is to say for at least more than a week, and immerse themselves in the culture of the place (Kennett, 2002). This is especially applicable to international travelers (students or others) who can be categorized as culture tourists. Featherstone (2002: 1) describes a "culture tourist" as someone dabbling in the culture of others. Language learners as cultural tourists share some of the characteristics of Cohen's (1979) experimental and existential tourists in finding comfort in another culture, although their physical and psychological base lies in their home culture. They spend time in distinctly non-touristic settings, like with local families ensconced in the language and culture of the hosts, thus interacting intimately with them. They have low visibility compared to other culture tourists, and they firmly reject a tourist label for themselves (Kennett, 2002). Their goals are more of an educational nature, with linguistic, cultural, and personal dimensions.

When there is a discussion of cultural tourism, the issue of authenticity is bound to surface. The concept of authenticity has, however, always been subjected to pressing debates about its true significance (Selwyn, 1996; Fawcett \& Cormack, 2001). It is the researcher's belief that language is intricately tied to the cultural heritage of a place and 
can be construed as one of the necessary constructs involved in experiencing the authenticity at a toured place. It thus follows from the above discussion that the study of language and its relevance as a salient component of an authentic tourism experience can best be undertaken within the context of cultural tourism and the tourist's quest for and experience of cultural authenticity.

Cultural tourism and authenticity. According to Selwyn (1996), there is an unresolved problem in research: the nature of tourism authenticity. Although theorists have widely suggested that the search for the ultimate tourist experience is a quest for things like authenticity, center, meaning, and values, authenticity itself has been an issue of contention among researchers for a long time. Different studies have claimed authenticity as being different things. In the past and according to previous researchers, to be authentic signified the property of being genuine, real and true. However, authenticity in tourism literature then seems to have evolved into a much broader context of being seen to be related to culture, people, heritage, events, traditions and placeproducts. Some of the views on authenticity are in terms of the objects themselves, others in terms of the authorities certifying and presenting the objects as authentic, and still others on the perceptions of the tourists (MacCannell, 1973; Bruner, 1994; Wang, 1999; Chhabra, 2008).

Wang (1999) defines three different types of authenticity sought by tourists as: objective, constructive (symbolic) and existential authenticity. Objective authenticity involves the toured objects while constructive authenticity deals with the symbols of authenticity, and refers to the assignation of authenticity by tourists to things which 
represent authenticity (for example souvenirs from tourist places like Ground Zero and local art products that are mass produced). Existential authenticity, however, involves the experiences of the tourists (their perception of authenticity and satisfaction derived accordingly).

This study focuses on the concept of existential authenticity defined by Wang (1999), which involves a potential existential state of 'Being' which is activated by the tourist activities. Objective authenticity stresses on the genuineness of the toured objects whereas constructive authenticity is a result of social construction, not an objectively measurable quality of the visited site. However, existential experience involves neither, and is centered on personal or inter-subjective feelings activated by the liminal process of tourist activities, in which people consider themselves more authentic and more freely expressed than in everyday life since they are engaging in non-ordinary activities free from the routine of their daily lives (Wang, 1999). Here, the authenticity of the seen or experienced phenomena is constructed in terms of points of view, beliefs, perspectives, or powers of the travelers. In this case, it is irrelevant whether the experience involves a construct that is genuine according to experts of the field, for example, the exact reenactment of a traditional dance being engaged in by tourists, or the genuineness of a toured object (Wang, 1991). Instead, the stress is on the construct being involved in a touristic activity that lends value to the authenticity of the experience for the tourist, and thus constitutes an alternative source of authenticity for the tourists (Wang, 1991).

Kennett (2002) cites studies (Clifford, 1997, Schumann, 1998) where the researchers spoke about identity changes owing to the practices of travel and interaction 
with the hosts, and that of MacCannell (1976) to claim that the language learners who stay with the hosts are closest to experiencing authenticity in the purest sense. For some tourists, the cultural authenticity might be related to the evolution of the norms and practices caused due to globalization, whereas for others, especially if their roots are from a different culture than the one they are presently part of, cultural authenticity might need to adhere to the norms and practices of the past. The intention of this study is to determine if the motivation to seek authenticity in their travel encourages tourists to speak the host language, and favors interaction with the hosts in their native language. The basic assumption is that tourist experiences related to the language spoken at a place involve discourse that relates to the cultural authenticity desired by them, which in turn stems from their motivations and attitude as a tourist.

\section{Language, Discourse, and Communication}

Language has a special place in the culture of a place/society. Languages live in places, and are attached to the sensuous, material features of the place (Abram, 1997). By definition, language is a system for communication, using sounds and/or symbols that have arbitrary yet structured meanings. Being a social phenomenon, it cannot be learned apart from social interaction (Phipps, 2006). Language is recognized as the chief vehicle for the transmission of culture, and creator and organizer of experience (Phipps, 2006). Thus, language, like culture, leads to shared meanings: when accepted, used, and understood by both parties.

It must be noted, however, that interactions between people who may even speak the same native language can be fraught with miscommunication owing to the subtle 
nuances or differences that are added to the language by an individual or community using it. It is thus safe to assume that in the instances where speakers differ in terms of their native languages, misunderstandings are generally expected to arise even more frequently (Mauranen, 2006).

As Li (2000) describes in the case of geographical consciousness, experiences of places, spaces, and landscapes are experiences of geography, whether or not it is a formal science, and form the phenomenological basis for geographical consciousness. This same thought can be extended to the interactions between tourists and hosts. These interactions, whether unpleasant or pleasant, whether consciously initiated or naturally happening, are thus experiences of language that form the phenomenological basis for linguistic consciousness.

Language in tourism. Tourism is a hugely global and massively multilingual phenomenon, and is ripe with the opportunity to engage with others in different contexts and different languages. Cronin (2000) contests persuasively that among other faculties that come into play in tourism, language and its imaginative potential hold a special place. Phipps (2006) calls the learning of languages and their actual use the "languaging" practices of tourists. It is important to study this phenomenon to understand the wider social and cultural factors at play in tourism experiences whereby tourists make sense of, and make an effort to get somewhere, by using the language of a place to talk to locals.

A language is "languaged" when it is learned, possessed, inhabited, and performed. It involves stepping outside one's comfort zone, letting go of one's inhibitions, and taking chances. The author contends that languages enable skillful 
interaction and efficacy in human activity, and although there is literature in the study of language pedagogy and language acquisition, the context of languages learned for and by tourists is practically untouched. "Learning to order a cup of coffee", something that has come to represent tourist language learning, has been looked upon as frivolous and not up to par with serious language teaching (Phipps, 2006). But the author contends that tourism, being the multilingual and inter-cultural phenomenon that it is, and the world's largest industry at that, tourist language-learning deserves its own place in the literature and research. The process of way-finding and role playing are essential processes in the tourist experience, and so are human relatedness and the engagement of tourists with the locals and the place. Student-travelers form a segment of tourists that represent this kind of language-learning, but on a much deeper cultural level. But this phenomenon too remains unexplored and has not as yet received the attention it deserves.

Anthropology has lamented the negative influence of tourism in that it destroys cultural and linguistic diversity (Dann, 2004; Russell \& Wallace, 2004; Snow, 2004, Turton, 2004). However, even though the number of students of modern languages (other than English) is decreasing, the increase of mobility across international borders has encouraged the learning of languages for tourist purposes, and this indicates a revival of interest in foreign languages, and in maintaining, not destroying cultural and linguistic diversity at the toured places.

Byram (1997) talks about the value of experiences of residence-abroad for foreign-language learners, indicating the significance of immersion in the local culture to learn a language in its most natural setting for a more effective learning to take place. 
Surprisingly, the literature on languages and residence abroad does not include any reference to tourism as a key feature in encounters with other cultures. Tourism is certainly an important and valid mode of critical, reflective, and educational engagement with the world. It would therefore be interesting to extract data supporting these claims from narratives that would constitute rich sources of information about the contexts in which the interactions take place and other factors at play. It is strongly felt that simple quantitative surveys, that have little room to obtain the complete context within which interactions take place, will be insufficient for the purpose of this research.

\section{Summary}

Tourism is a significant platform for intensely multilingual and highly intercultural experiences. Different tourists have different motivations to travel, among which cultural tourism and the search for authenticity are of primary concern for this study. Speaking the language of the visited destination is an obvious advantage, and international tourism encourages learning of languages for tourist purposes, especially when tourists travel for cultural or related reasons.

However, acceptance or status of English as lingua franca, or the universally spoken and understood language, makes it increasingly unnecessary to learn another language for tourism purposes. As Nunez (1977) argues, the acquisition of a second language for purposes of catering to tourists is more prevalent than that by tourists for the purpose of interacting with the hosts. This study will further explore this issue and try to understand the reason for more focus on tourist language in the tourism industry as well as tourism literature than on the host language, and if this has to do with the tourists' need 
or desire (or lack of it) for immersion in the host world. Further, the research is undertaken to learn more about the importance of the host language to tourist experience for the tourists themselves. Literature on languages and the language crises, and the practice of learning other languages has next to no mention in the literature on international tourism. Conversely, even though tourism represents a massively multilingual phenomenon, the role of language in tourism is potentially untouched by researchers who confine themselves to writing about the lack of language skills in its servants, and to critical assessment of patterns of discourse and its potential symbolic violence. Thus, modern linguists, for the most part, ignore tourism in their research, and tourism scholars ignore language in theirs.

Languages and tourism, as forms of intercultural learning, shape the everyday life of tourism as well as its tactics and strategies (de Certeau, 1984). Speaking the language of the hosts could deepen the potential for tourists' relations with another people and place. This research addresses tourist language learning in the cultural context, which deserves its own place in the literature and research on tourism as well as linguistics.

Phipps (2006) contends that mass tourism, ordinarily, doesn't have any mindbroadening impact on tourists. It involves hedonism and conspicuous consumption as opposed to learning and understanding other cultures (Crik, 1996: 33-4). However, if the tourist motivations involve learning and the search for authenticity, the tourists show an interest in immersion in a place's culture. This kind of tourism, therefore, is educational and can have a mind-broadening effect. The cultural tourists thus become cultural sojourners, affecting and in turn being affected by the social dynamics in the host society. 
This transformative power of tourism is more a speculation than something established from people's narratives. This study takes that step and delves into the experiences of study-abroad students to gain an insight into the role of language in shaping cultural experiences. Their views, modernist or postmodernist, and their tourism experiences, are the focus of this research.

The desire to learn a language and speak it in its natural setting motivates travel (Dornyei, 1990). In a related manner, the tourism experiences could have future implications for the travelers since they might motivate travelers to learn the local language in order to prepare them better for their future travel experiences.

It makes logical sense to master a language through immersion in the culture of the place where the language is spoken locally/colloquially, but little research has touched upon the importance of tourism in sharpening linguistic skills. On the other hand, since communication is an essential part of tourism, it can be speculated that language greatly affects the tourist experience when the tourist language is different from the local language, and there might be a lot that is lost in translation.

It is interesting and worthwhile to research the ways in which communication can still happen, but as pointed out by one of the participants, there is a part of a person's personality that is missing when that person is not entirely fluent in the language or familiar with the cultural intonations. It is felt by the researcher that it will be useful to utilize sociolinguistic theories to explore the particular role that language plays in defining cultural tourism experience. Further, it would be interesting to study whether the knowledge of a place's language adds to, or the ability of the host to speak the tourist's 
language hinders, the authenticity of the experience or the overall satisfaction with the place. 


\section{Chapter Three}

\section{Methods}

Phenomenology can be defined as a discipline that studies the structures of experience, or consciousness. Literally, phenomenology is the study of "phenomena": appearances of things, or things as they appear in our experiences. It is the study of the ways in which we experience things, and therefore of the meanings these things have in our experiences. Phenomenology studies conscious experience as experienced from the subjective or first person point of view (Creswell, 2007). The application of phenomenology has not been extensive in tourism research as yet. Qualitative researchers, however, find it very useful in understanding different phenomena by analyzing the rich details in narratives obtained from research participants. It was felt that an in-depth understanding of the different phenomena involved in the process of tourism could be achieved by employing phenomenology and thus it formed the basis of the methodology that was employed in this research. The approach felt suitable for a phenomenological study was that of transcendental phenomenology and stress was placed on description, not interpretation of the participants' experiences (Creswell, 2007). The methodology adopted for this study was narrative ethnographic methodology (Elliot, 2005). Narrative ethnographic approach focuses on how people perceive experiences and on the meanings they make of the experiences, evident in the process of recounting them; and not why they perceive what they perceive through their interactions during the act of tourism. 


\section{Research Design}

The quantitative measures employed by other researchers are extremely useful in exploring the interrelationships between various variables being studied. However, it was felt that an in-depth understanding of the phenomenon of the impact of language on tourism, as is the aim of this thesis, required qualitative methodology for data collection and analysis. This is because the goal of this study is to explore and understand the meanings that tourists make of their experiences in the context of linguistic interaction with the host. The goal is also to investigate the various underlying issues highlighted by the difference in travel motivations and expectations as well as the relationship of these motivation and expectations with the tourists' knowledge of the local language. A semistructured interview design was chosen for the flexibility it imparts to the flow of the narratives (Babbie, 2007). It was also felt that a semi-structured approach would provide the co-researchers with the freedom to share their travel experiences, while at the same time steer the conversation back to the research at hand in case of extreme digression.

\section{Interview Questions}

The following interview questions were designed to be open-ended, allowing the co-researcher to speak freely. They were, however, driven by the study at hand. These questions were designed to obtain information about the past, present and future travels of the student-travelers, not one trip alone.

- What made you decide to travel abroad as part of this program?

- When you think of culture, what comprises a place's culture for you? What are its basic components, and what place does language possess in this context? 
- Can you please talk about your tourism experiences in (country name)?

- Can you please talk about the times when you were aware of language differences and what were some of your experiences at that time?

- Probes: Can you please talk about the times when language presented a challenge? Can you tell me about the times when language enhanced your experience?

- Please talk about your interactions with the host community (residents of the destination vs. service providers)? (If they are staying with the hosts, they would be encouraged to talk more about it and also to relate past experiences or future preferences based on those experiences in similar settings).

- Probes: Describe any memorable episodes that affected your experience favorably? Describe any unfavorable incidents with the hosts (for example episodes of miscommunication).

- Was the level of interaction you desired with the locals affected by your knowledge or lack of, the host language? How comfortable are you with cultures/people who speak a language different than English?

- How do you make sure you maintain the level of interaction with the local population (residents, not service providers) you desire? If you do not desire much interaction, what steps do you take to ensure you do not have to interact much with the locals?

- What was your interaction with other students, local or international, like?

- Please share the kind of preparations that you did related to studying the host country's language before traveling overseas. 
- Please share your educational experience with us. Please relate how the difference in the spoken language affected your educational experience.

\section{Sampling method}

For this study, 13 student-travelers who traveled abroad as part of the Study

Abroad Program at SJSU were chosen to be interviewed. As mentioned previously, the rationale for this sample is that these students are also travelers, and they are from the United States where English is the primarily spoken language. The student-travelers were at different levels of proficiency with the spoken language at the country visited, and some did not know the language at all when they started. In addition to that, these students traveled to the host countries for reasons related to experiencing a new culture, whether or not it primarily involved learning the host language.

The participants were recruited from the population of study abroad students at San José State University. A request for participation was distributed to the SJSU Study Abroad Program participants (ranging from 2008-2011), and also to students in all the different departments in the College of Applied Sciences \& Arts. A recruitment email was forwarded to students via staff members at the Study Abroad Program office at SJSU and faculty members at the College of Applied Sciences and Arts. In this email, the researcher explained the purpose of the research study and expressed an interest in interviewing students who had been part of study-abroad programs to foreign countries where the spoken language was different from English. These students traveled to a foreign country for a period ranging anywhere from a month to about 1 year, and undertook learning the host language through immersion in the culture of the native 
place, whether or not this was the main focus area of study for them. Students who attend college in another country for a semester or more are considered exchange students and were also considered student-travelers for this study. Exchange students are inclined to pursue their courses, which are most commonly courses in a foreign language, in the local setting for purposes of cultural immersion. (Dornyei, 1990) claims that students interested in second-language acquisition are interested in wider social contact. Further, they regard international tourism as a means to this desired intercultural contact, which enables them to acquire better language skills through immersion in the culture of the place. The rationale for this is interlinked with the findings of his study that proposed that intercultural contact, generated primarily by international tourism, is related to interethnic and language attitudes, and subsequently to second language learning motivation, and is in turn motivated by it (Dornyei, 1990). Thus, students who undertake travel to a foreign setting with the purpose of cultural immersion were desirable for this sample of student-travelers, especially since it was felt that an analysis of their experiences would shed more light on the perception of significance of language skills and intercultural contact in the international tourism domain.

Once the co-researchers were interviewed, they were requested to refer their friends who fit the sample profile and were willing to share their foreign travel experiences. Thus, the original set was expanded through snowball sampling. The student set included travelers who fit different learning levels, ranging from basic language or survival skills to advanced language skills. Conscious language learning during the trip was common to all the subjects. 
The prerequisites for the sample were that:

a. The co-researchers/participants must be native English speakers

b. They must have traveled internationally to any of these countries: France, Italy, Spain, Hong Kong, Costa Rica, Sweden, Finland, Chile, Argentina, China, and or Japan (or a country whose native language could be learnt in schools in the US, and is also part of the Study Abroad Program at San José State University)

The goal was to analyze the data obtained and to describe the common experiences shared by these travelers; to describe the role that language plays in enhancing their experiences as tourists, to understand the role that language could have played in enhancing their educational experience, and to uncover the challenges faced by the student travelers as a result of language differences. Given that language is the focus of travel for the participants, it was felt that information on the role that it plays in shaping their experience of the toured place will be more easily obtained. In the case where language wasn't the primary focus, there was an effort to learn it prior to or during the visit, since if not the case, the sensitivity of the participant to the significance of language would not have been very enhanced. The sampling for study participants included advertising for study participants, primarily with the help of the Study Abroad Program at San Jose State University. More subjects were contacted through references made by the interviewed student travelers, in other words, through snowball sampling. There was no effort to stress on the nationality of the co-researchers themselves but they all had to have English as their native language. 


\section{Data Collection}

The first step of the interview process was to collect basic objective information in the form of a questionnaire. The questionnaire collected information on the place visited, the program with which the student tourist traveled, the student's major in college, the focus area of study abroad, the purpose of the visit, and the duration of the visit. The interview itself was designed to be exploratory, qualitative, phenomenological, and semi-structured. Since the tourism experience of each participant was considered unique, and personal, the participants of the study were encouraged to share their experiences freely. However, a general direction of questioning was provided to gather information relevant to the focus area of the study.

The participants were regarded as co-researchers, in order to acknowledge the nature of this ethnographic methodology, where the interaction of the interviewer with the interviewee is as important as the experience recollection and the narrative of the interviewee. The participants were also referenced as student-travelers since they are essentially travelers who are also student learners. In place of sampling theory, the coresearchers were selected on the basis of their willingness to participate in the study, and based on whether their profiles fit the sampling requirements for choosing them $(\mathrm{Li}$, 2000). Single interviews were conducted and ranged from 45-90 minutes on an average. A second interview was conducted if the need to gather more information was felt after conducting the first interview.

Since descriptive words may be imprecise, ambiguous, and/or open to multiple interpretations, soundness of phenomenological study calls for attention to the procedures 
employed for data gathering and analysis (Li, 2000). Semi-structured interviews were conducted in English from March 2010 to September 2011. They were digitally recorded and transcribed verbatim for analysis. Other techniques were employed to improve the robustness of the data, such as taking notes during and after the interviews, and journaling. Writing notes and memoing using a computer software program helped with tracking emerging patterns and relationships between different broad themes that emerged immediately following transcription. The subsequent interview transcriptions were made more robust by providing context about the relationships of the student travelers with other international tourists, local hosts, and fellow American students. The analysis involved fragmenting the raw data into significant statements, also referred to as horizontalization of data (Creswell, 2007), labeling these discrete parts. In other words, these statements were coded; labels/codes were organized into conceptual categories and sorted to narrow down the core categories. This resulted in the identification of recurring significant and relevant themes in the analysis of data.

\section{Trustworthiness}

The interviews were transcribed verbatim using a transcription machine in conjunction with Evernote. Each transcription was completed and sent to the participant for a member check, corrections, and clarifications (Babbie, 2007). As the interviews were transcribed and reviewed, some study participants were contacted via e-mail for additional questioning or clarification. Personal blogs and online journals of some participants were also analyzed for further insight into their experiences, when available. This was done in order to corroborate and triangulate the findings. Participants that 
showed active interest in the research findings participated in the review of a rough draft of the findings, and provided feedback. Peer reviews were requested to ensure trustworthiness. In order to avoid researcher bias and to isolate her personal experience, the author recorded her experience with the San Jose State University study abroad program at the beginning of data collection process. To increase reliability, the researcher maintained a journal during data collection and analysis for the purpose of addressing researcher bias that might arise due to relevant personal experiences. The journal helped to record emerging ideas and perceptions as research progressed. Trustworthiness and credibility of the data were thus improved by various means outlined above.

\section{Data Analysis}

A grounded theory approach (Babbie, 2007; Glaser \& Strauss, 1967; Strauss \& Corbin, 1998) to data analysis was undertaken since the study was exploratory, and the data collection seemed to indicate emerging patterns and themes. These patterns and themes were found to be amenable to effective consolidation by means of a systematic and scientific approach to data organization and analysis, while simultaneously allowing for creativity in the process (Strauss \& Corbin, 1998). This approach is uniquely well suited for this exploration of the role of language in shaping tourism experiences because of the inherent subjectivity involved in this study. However, despite the uniqueness of people's views and experiences, several common underlying factors were found to govern the attitudes and creation of these tourist experiences. This provided ample opportunity for usage of inductive reasoning strategies (Babbie, 2007) to report the findings in terms of the role of language in shaping these tourism experiences. 
The four-step constant comparative method proposed by Glaser and Strauss' (1967) was utilized since it allowed for multiple concepts to be compared and grouped and integrated into discrete and condensed categories. These categories pointed to overarching themes that were ultimately tied together to propose an understanding of the phenomenon under study (Babbie, 2007).

Memoing (Strauss \& Corbin, 1998) using Evernote software program was first applied during the interview process and continued throughout the data collection and analysis stages. These memos consisted of detailed analytical notes, code notes, and served as the preliminary organization and consolidation of the raw data present in interview transcripts, author's interview notes and journal, and online journals and/or blogs of the participants. The analysis process was devised as "flexible, iterative, and continuous" (H \& R. Rubin, 1995, p. 43 as cited in Babbie, 2007).

The transcripts were initially open coded to establish the different concepts and themes that emerged from the initial analysis. These included earlier exposure to the host-language in the home country, motivations to travel, the perceived significance of the host language and of interaction with the locals, the role of language as a facilitator of the desired tourism experience, and the role that language plays in preventing the studenttraveler from the tourism experience they desire.

One hundred and forty four single spaced pages of transcripts were then reduced to 57 pages of memos. These memos constituted a rewriting of the transcript in terms of the author's notes and perceptions in regards to the interview data as well as actual quotes from participants. These memos were then used to organize the text in the form of core 
categories in an excel spreadsheet. The initials that originally identified each respondent were changed to names and then pseudonyms. The responses of each student-traveler were analyzed for recording individual experience parameters, and factors influencing their experiences, primarily in terms of the role of the host language.

Next, axial coding was used to refine and consolidate the initial categories and create new ones as distinct subcategories became apparent from the analysis. The broader category of "cultural experience" was, for example, consolidated to reflect the authenticity perceived in the tourism experience.

Finally, selective coding revealed patterns, similarities, and differences across the initial broad categories and from one co-researcher to the other. Dynamic relationships among linguistic ability, travel expectations, and tourism experience dimensions were evident as each individual's portrait was analyzed, indicating complex inter-relationships that made mutually exclusive categorization unnecessary.

The initial and subsequent more focused coding was achieved throughout the process of analysis using Glaser \& Strauss' (1967) constant comparison method. In addition, the reflective journal was used to record insights, thoughts, and perceived patterns to generate further research questions as the results unfolded. The reflective journal also served the purpose of revealing author bias and personal attitudes regarding the subject matter.

\section{Summary}

Thirteen study-abroad students were interviewed using semi-structured interview techniques for this exploratory qualitative study of the role that language plays in shaping 
a student tourist's tourism experience in a foreign country, where the host language is not English. Once the interviews were transcribed verbatim and member checks took place, the data was coded and analyzed utilizing grounded theory methods as applied through Glaser and Strauss' (1967) four-step constant comparative method. Memoing and a reflective journal augmented the process. 


\section{Chapter Four}

\section{Findings}

\section{"Someone from Spain thought I was from Argentina because I really picked up the}

accent, and I loved that." (Pam)

The findings of this study will be discussed in the context of the study purpose outlined in Chapter One. Thus, the guiding research questions served as the basic framework for a discussion of the findings. It will involve a discussion of various thought processes that reflect the travel motivations involved in making the decision to travel to the various study-abroad locations, how students conceptualize and verbalize cultural authenticity, and the significance of the visited country's culture to their travel. This discussion will be followed by a segment on the perception of student travelers, in regards to the significance of language and discourse involving local people with respect to their travel experience. Finally, this section will discuss the findings regarding the influence that language has on the interaction of student-travelers with the hosts, and the shaping of their tourism experience. This will involve a detailed discussion of how language facilitates or hinders the creation of the tourism experience that the studenttravelers desired.

The student-traveler sample included students who had traveled to varied foreign destinations with host language different than English in each case, while all had English as their first language. Table 1 summarizes the reasons for travel to these places as indicated by the student-travelers, the places they traveled to, and the native tongue at those places. It should be noted that the real names of the participants were changed to pseudonyms as represented in the table below and throughout the thesis. 
Table 1

Motivation to travel, place of travel and the host language

\begin{tabular}{|c|c|c|c|}
\hline Student-traveler & Travel motivation & Host country of travel & Host language \\
\hline Pam & $\begin{array}{l}\text { Better her Spanish, } \\
\text { learn more about the } \\
\text { culture; Wanted to go } \\
\text { to Argentina }\end{array}$ & Argentina & Spanish \\
\hline Harry & $\begin{array}{l}\text { Escape boredom of } \\
\text { everyday life }\end{array}$ & Sweden & Swedish \\
\hline Minh & $\begin{array}{c}\text { Cultural experience, } \\
\text { wanted to travel } \\
\text { outside the US }\end{array}$ & France & French \\
\hline Kristin & $\begin{array}{l}\text { Cultural enrichment; } \\
\text { Language (French) } \\
\text { learning and usage }\end{array}$ & France & French \\
\hline Joan & $\begin{array}{l}\text { Wanted to travel } \\
\text { outside the US, } \\
\text { especially to France }\end{array}$ & France & French \\
\hline Monica & $\begin{array}{l}\text { Study French and } \\
\text { live in France }\end{array}$ & France & French \\
\hline Cindy & $\begin{array}{l}\text { Wanted to go abroad; } \\
\text { Food culture and } \\
\text { bettering her } \\
\text { Cantonese }\end{array}$ & Hong Kong & Cantonese \\
\hline Sharon & $\begin{array}{l}\text { Wanted to go to a } \\
\text { Spanish speaking } \\
\text { country in Europe, } \\
\text { since she is fluent in } \\
\text { Spanish. }\end{array}$ & Spain & Spanish \\
\hline
\end{tabular}




\begin{tabular}{|c|c|c|c|}
\hline Kate & $\begin{array}{l}\text { Visit another } \\
\text { country, especially } \\
\text { France because of } \\
\text { French (piano) } \\
\text { music; Had learned } \\
\text { French prior to } \\
\text { traveling. }\end{array}$ & France & French \\
\hline Amy & $\begin{array}{l}\text { Wanted to see } \\
\text { something new, } \\
\text { Experience a new } \\
\text { culture, meet new } \\
\text { people, had studied } \\
\text { French in High } \\
\text { School }\end{array}$ & France & French \\
\hline Angelina & $\begin{array}{l}\text { Studying Spanish } \\
\text { since the language } \\
\text { was her minor in } \\
\text { school, Always } \\
\text { wanted to travel to } \\
\text { Spain, }\end{array}$ & Spain & Spanish \\
\hline Betty & $\begin{array}{l}\text { Study environmental } \\
\text { science, wanted to go } \\
\text { a country with a } \\
\text { different feel than } \\
\text { the United States }\end{array}$ & Finland & Finnish \\
\hline Vivian & $\begin{array}{l}\text { Better her Japanese } \\
\text { and cultural } \\
\text { knowledge, wanted } \\
\text { to travel outside the } \\
\text { United States like } \\
\text { other family } \\
\text { members did }\end{array}$ & Japan & Japanese \\
\hline
\end{tabular}

\section{Exposure to the Host Language}

Table 2 below summarizes the extent of exposure each student-traveler had with respect to the local language spoken at the host destination. In some cases, the studenttravelers had formally learned the foreign language at school for several years, or taken it as a minor or major area of study at college, while in other cases the student-travelers 
spoke the language or were exposed to it from an early age. A few student-travelers had no contact with the host country's language before traveling. However, either their programs involved language classes offered at the study abroad location to help the student-travelers adjust to the language barrier effectively, or the student-travelers decided to personally enroll in a language class at the host destination. In most cases, the exposure to language of the host country played a significant role in influencing the decision to travel to the specific country. Even if the decision wasn't centered on learning the language, it was often inspired by a keen interest and sometimes fluency in the local language.

Table 2

\section{Exposure to host country's language, place of travel and the host language}

\begin{tabular}{|c|c|c|c|}
\hline Student-traveler & $\begin{array}{l}\text { Host country's } \\
\text { language }\end{array}$ & $\begin{array}{c}\text { Formal exposure } \\
\text { before traveling } \\
\text { Pam }\end{array}$ & $\begin{array}{c}\text { Informal exposure } \\
\text { before traveling }\end{array}$ \\
\hline Spanish & $\begin{array}{c}\text { Pursuing a Master's } \\
\text { degree in Spanish. }\end{array}$ & $\begin{array}{c}\text { Time spent in Spain, } \\
\text { living in the bay area. }\end{array}$ \\
\hline Minh & French & $\begin{array}{c}\text { None (Crash course } \\
\text { in Sweden before } \\
\text { his classes started) }\end{array}$ & None \\
\hline Kristin & French & $\begin{array}{c}\text { Studied French in } \\
\text { high school. }\end{array}$ & None \\
\hline Joan & French & $\begin{array}{c}\text { Studied French in } \\
\text { high school. }\end{array}$ & None \\
\hline Monica & French & $\begin{array}{c}\text { Studied French in } \\
\text { high school and at } \\
\text { SJSU. }\end{array}$ & $\begin{array}{c}\text { Been to France once } \\
\text { before. }\end{array}$ \\
\hline
\end{tabular}




\begin{tabular}{|c|c|c|c|}
\hline Cindy & Cantonese & None. & $\begin{array}{l}\text { Her family speaks } \\
\text { Cantonese. Spoke } \\
\text { Cantonese with them. }\end{array}$ \\
\hline Sharon & Spanish & $\begin{array}{l}\text { First language is } \\
\text { Spanish. }\end{array}$ & $\begin{array}{l}\text { Spoke Spanish at } \\
\text { home and outside. }\end{array}$ \\
\hline Kate & French & $\begin{array}{c}\text { Studied French } \\
\text { before traveling to } \\
\text { France. }\end{array}$ & $\begin{array}{l}\text { Listened to French } \\
\text { piano music and knew } \\
\text { about composers. Not } \\
\text { exposed to the } \\
\text { language per se. }\end{array}$ \\
\hline Amy & French & $\begin{array}{l}\text { Studies French in } \\
\text { high school and at } \\
\text { SJSU. }\end{array}$ & None. \\
\hline Angelina & Spanish & $\begin{array}{c}\text { Minoring in } \\
\text { Spanish at SJSU. } \\
\text { Studies Spanish in } \\
\text { high school. }\end{array}$ & $\begin{array}{c}\text { Spoke Spanish with } \\
\text { her Father who knew } \\
\text { some Spanish. } \\
\text { Watched Spanish TV } \\
\text { game shows. }\end{array}$ \\
\hline Betty & Finnish & $\begin{array}{l}\text { None. Took a } \\
\text { course in Finnish in } \\
\text { Finland. }\end{array}$ & None. \\
\hline Vivian & Japanese & $\begin{array}{l}\text { Studied Japanese at } \\
\text { SJSU as her major. }\end{array}$ & Japanese \\
\hline
\end{tabular}

\section{Travel Motivations}

Different student-tourists traveled with different motivations. Whereas a few wanted to just go and visit a different country outside the United States, some gave more thought to their expectations from their experience, were mindful of the difference in the culture and language and even prepared to handle it. Almost everyone wanted to meet new people and learn about a new culture, different from the one they were familiar with. Language 
learning was involved in all the cases, whether before or during the program, or both. The studying abroad experience was the common factor connecting them. As seen in all the cases, the different travel motivations, affected each of their decisions to travel to specific destinations. Common motivations included (a) escape from boredom, (b) desire to experience a new country, (c) learning another country's language through immersion, (d) desire to learn about another culture.

Escape from boredom. One of the main purposes that traveling serves is to help a person break the monotony of life, and to escape to a new place where the change of routine is refreshing. For instance, Harry wanted to escape the boredom of everyday life, as did Joan. Sharon wanted to just go somewhere away from the United States. However, even when her motivation was to escape from her daily routine, she made Spain her base since it was the only Spanish speaking country in Europe, and she was already fluent in Spanish.

Experiencing a new country. Many of the student-travelers had never been outside the United States, and went with the program because they wanted to travel outside the country. Since there are different study-abroad programs of varying lengths and cost-structures, students are usually able to travel to foreign countries despite time and/or money constraints. For Minh, who “just wanted to go just to go," there weren't any self-defined motivations. However, she was excited about the trip because she had never been outside the United States before but had always wanted to go to France, particularly Paris.

Vivian wanted to get out of the United States and study abroad like her other 
family members had done or were doing at the time. It was similar for Sharon, who said, "I kind of just wanted to leave the US, to be hundred percent honest with you. I wanted something different. Spain just seemed like an adventure.” Cindy says, "I don't think location was as important as just going, just experiencing stuff." However, she intentionally and consciously picked a country where she could focus on the language she thought was important to learn.

Pam wanted to travel outside of the United States, to a place where she would get the opportunity to speak Spanish with people on a daily basis. Having lived with an Argentinean family on her previous study abroad trip to Spain, Pam had developed a deep affinity for their culture, and that made her very interested in finding out more about their history and in experiencing the culture. Furthermore, it was a great opportunity to speak Spanish in a local, more natural setting. Thus, she chose to travel to Argentina for her study-abroad.

Since there are different study-abroad programs of varying lengths and coststructures, students, who want to travel to foreign countries are usually able to travel despite time and/or money constraints. Pam went to Argentina for a six-week program with International Student Exchange Program at SJSU. She would have liked to go for a longer period of time but this program suited her better since she is married and works, and couldn't be away for too long. But her main motivation was to work on her Spanish language skills by living in a community that spoke Spanish on a daily basis.

For another participant Minh, who traveled to Paris, France, the one-month long program offered a great opportunity since it was the first time that she was leaving the 
country, and she was comfortable with the duration of her stay away from her family. She felt that the cost of the program and the comfort of traveling in a group were important factors for her to decide in favor of the Summer Study Program.

Kristin, who did not want to be away from her family for a long period of time, found that the program met her expectations and still afforded her enough time in France to gain a deeper understanding of the French culture. For Betty, cost considerations prompted her to look into programs with SJSU, and the program at Finland allowed her to pursue a major she wanted to with some added school benefits. She adds, "It's fairly affordable. I also was looking for a country where I could study in English. I found Finland. I think Finland was such a great choice for that (to go to a country with a different feel than the United States).”

Cindy picked Hong Kong over her other choice (Germany) for several reasons, such as, "Traveling in South East Asia was a lot cheaper than traveling through Europe." For Amy, the study abroad program she traveled with was perfect for her. Since she had studied French in high school, her country of interest was France, and she found a program for her major in Lille, France. On top of this, it was through school and she could transfer credits for all her coursework there to SJSU.

Joan, who was 21 at the time she traveled to France, just wanted to travel to France as soon as possible. Having studied French in high school and wanting to continue doing so in college, Joan wanted to travel to a French speaking country. She regarded learning French as a hobby and wanted to go to Paris but didn't have the knowledge of French needed for the program in Paris. As a result, she traveled to Aix-en- 
Provence in France with the Study-Abroad program at SJSU.

Vivian traveled to Japan since she was learning Japanese, which is also her major. Angelina traveled to Spain instead of Australia when she got a second chance to choose the country, since she was minoring in Spanish. She thought it was more beneficial to be in a Spanish speaking country so she could practice and improve her Spanish along with taking courses in her major (nutrition). She also always wanted to travel to Spain after hearing about people's lifestyle there from her high-school Spanish teachers.

For Sharon, it was a matter of comfort and convenience where language was concerned. Although she just wanted to travel and get out of the country, she says, "I felt like that was the only place I could go in Europe where I might fit in just because of the language. And I wouldn't have a language barrier. That's basically the biggest reason behind it: that I felt that I could communicate with people." Thus, although she traveled all over Europe, she decided to do her study-abroad experience in Spain.

Learning another country's language through immersion in the culture. The student-tourists who were fluent in the local language were determined to be able to speak and sound like a local. They wanted to listen to the hosts, and talk like them. Monica wanted to understand the nuances of the language, and the rules that drive the way people spoke, and insisted that to achieve a mastery level, she had to get out of the United States, and live in a country where they spoke French every day.

Pam and Vivian wanted to better their Spanish and Japanese respectively, through exposure to the languages and interaction with the locals in their natural settings. Cindy, whose grandparents spoke only Cantonese, wanted to work on her Cantonese to be able 
to talk to her relatives. As Cindy puts it, "when I was applying, I had been looking at different locations, but in particular I was looking at Hong Kong and Germany, because I wanted to improve my language skills. I ended up following on Hong Kong because I had heard about the food culture, and there was the family aspect for me." For Cindy, who wanted to be able to converse with her grandparents in the language they were most comfortable in, it was a matter of picking up everyday language skills, and she thought that the exposure to Cantonese in Hong Kong would be perfect for that.

Cynthia: It was a little saddening when I couldn't hold a five minute conversation with my grandparents. I was like, 'I know what you are saying but I can't.' I couldn't reply back in Cantonese. I knew how to reply back in English, I even knew how to reply back in German because my speaking skills in German had gotten better than my Cantonese. So I was like, 'Ok, fix this.'

And it was in order to address this problem that she decided to travel to Hong Kong and work on her Cantonese speaking skills. All three student-travelers desired a day-to-day contact with the language, and to talk to native speakers in their own setting, where the language they wanted to master was the local language and was spoken every day. Pam felt that traveling to a country where the everyday spoken language was Spanish would give her a better opportunity to work on her Spanish skills.

Pam: I am getting my master's in Spanish, and I realized from a past study abroad experience (in Spain) that the level of knowledge that you learn is so different when you live in a country versus practicing it for a few hours each day. And although we live in San Jose and there is a wonderful opportunity to practice 
Spanish here, the little things like going to the store, or trying to get on a bus, that you don't learn. And you know in basic courses you can go over vocabulary but these are more life skills, you learn how to interact with different people, and so I wanted to pick up on bettering the language versus just my courses in my Spanish class which are, you know, literature and history and things like that.

For Pam, it wasn't enough to live in a part of the United States where it is possible to speak Spanish but it is not the spoken language of the place. She wanted to be in a country where she needed to speak Spanish in order to communicate with the local people as part of her daily routine. She regarded this communication as essential to master the language, something she could not rely on her courses alone to help her achieve.

Monica felt the same way about speaking French: "I was hoping to achieve some mastery in French, because I had taken French before", and I felt like, "I am taking classes at San Jose State, it's fine and dandy", but you don't really necessarily get to the mastery level that you would living abroad (in a francophone country)." "Kate feels that it was music that drove her to Paris, since she was fascinated by a French composer's music. She adds, "I wanted to evaluate how French people live, (their) lifestyle, the rules and regulations, the patterns, like (when) they wake up, (also) the terrain of the place, the architecture."

Betty originally traveled to Finland to study her minor program in Environmental Studies. However, she ended up taking a course there to be able to interact with people more and understand their culture more closely once she realized that she liked their 
culture and wanted a closer look at it.

Angelina found herself in a completely different situation which led her to communicate extensively in the local language, Spanish. She found herself with no choice but to rely on her Spanish because she was in a small city in Southern Spain where people did not commonly speak English. Although interacting with the locals was tough for her initially, she was eventually content to be in that situation, because it gave her a chance to work on her language skills. Being able to speak Spanish fluently also allowed her to get a better understanding of, and exposure to the culture in Murcia.

Angelina: I am thankful I had that city for that reason, because I learned a lot more than if I would have been somewhere else. When I did travel to Barcelona and Madrid, I barely had to use any Spanish to get along. The workers (service providers), you know, in all the places that we visited, spoke English. They had to, for the tourists.

Angelina felt that the location for her study-abroad program worked out perfectly because of the progress she made in speaking the language in such a short time, and because it gave her the push to speak Spanish on a daily basis.

Desire to learn about a different culture. Amy, who had exposure to French in high school, decided to travel to Lille, France, for her study-abroad program. She wanted to experience a new culture and meet new people. She also wanted to see how the French culture worked and in what ways it was different from that of the United States. She also wanted to get close to the lifestyle and patterns of living and thinking in France and learn more about their culture in the process. Meeting new people and 
interacting closely with them, in order to get to know more about their culture, was a frequently occurring theme in the narratives of the student travelers. When asked to talk about culture, the student-travelers described it as a combination of a variety of elements such as the lifestyle of the people, their food habits, the language they speak, and the way they interact with each other.

Kristin and Minh wanted to go to France for similar reasons. Having heard about Paris and its wonders, Minh felt that the study-abroad program gave her the perfect opportunity to travel to the city, especially with a group and not by herself. For Kristin, it was a chance to hear French spoken in its natural, cultural setting, and a way to experience the language she had learned in high school. She thought that her knowledge of French, even if a little rusty, would help her understand the culture a little better. For Kate, who also traveled to France, the motivation was to experience the home of a romantic pianist she admired, to be able to live in the culture where he came from, and to be able to have an authentic experience.

Vivian says about Japan and its culture: "The way people interact is very different." She says about expanding her cultural knowledge and understanding Japanese culture: "It's just taking a new outlook on life, interaction with people in that kind of way I suppose." Angelina talks about her interest in a place's culture as well. She says, "I love learning about culture and just how people live day-to-day in other places, the feeling I get from the people that live there, or like you know when they wake up in the day, where people go, and where they eat, and what they do."

Most participants, however, either had earlier contact with the host language or 
studied the host language before or during their study-abroad programs, or both. This seemed to have made them more aware of the country and its culture as well as curious to explore and understand the culture of the place. Their facility with the host language was at different levels, and it seems to have affected their experience of the culture and place in different ways.

The next section discusses the findings of this research based on the second guiding question, which relates to the way the student-travelers perceive culture, and how they define it. Although the way they talk about their experience of cultural authenticity is not always explicit, the data collected through the interviews contains various allusions to their beliefs about culture and authenticity. These are discussed below.

\section{Culture and Cultural Authenticity}

Although the ways the student-travelers express their views about and interest in experiencing cultural authenticity do not always include the term 'cultural authenticity', their narratives reflect various allusions to this concept. Monica says, "I was hoping to just kind of become as much as a part of the culture and the town as I could, meet locals, and just experience what they knew every day." Student-travelers that had a keen interest in understanding a place's culture were also more inclined to meet and interact with locals, reach out to the local people, and try to mimic the local lifestyle. The various ways in which the co-researchers talk about culture and cultural authenticity are reflected in (a) their perception of culture, (b) their desire to interact with the local population and understand their ways of living, (c) doing non-touristy, more local things, (e) using the host language in their interactions, and (f) living like a local. 
Perception of culture. According to Amy, "Everything in a place is about culture, for example, the lifestyle of people." She adds that the food patterns, the way language worked, the sense of humor of the locals are all part of the culture for her.

According to Monica, a society's traditions; its food; its language; its learning, the nuances, not just of the language but what's behind that, so you are learning the rules behind why it is people act a certain way; and sort of just enveloping oneself in the everyday lifestyle, is experiencing the culture of a place. She gives an example of, "Just going every day to class and getting a little baguette, and you know a bottle of wine, and you are talking with people. French culture, from what I take out of it from my experiences is, such a big emphasis on interacting with people, constantly having interactions, going to a cafe, talking with people, and not just about mundane things, but actual politics, and life." She adds that language is not only a huge part of these interactions but also that of the culture itself.

Staying with a local family. For Pam, among other things, language is a big part of the culture. She feels very strongly about living with a family to get the real feel for a place. She says that living with a family gave her more access to the language and let her work on her knowledge of Spanish far more than other students. Her opinions on the matter are reflected in her words: "I wouldn't do it any other way. I think living with family also enhances the experience. For me because I haven't lived with roommates when I traveled but when I met people that were living with other friends they would speak English and I was speaking Spanish, so I was by far increasing my knowledge of the language." She also adds that she knew far more about the local hang-outs and places 
of interest such as the locals' market or the festivals that were going on at the time, things she had learned from the family she was living with.

Monica talks about students who lived in home stays, as a result of which they were able to find a different avenue to involve themselves in the culture. She says about her stay in the dorms that she certainly enjoyed it and it also helped her develop a different perspective through hanging out with many different students. At the same time, she feels that living in home stays was wonderful because the students got to know their French family, which was much different than hanging out with students all the time. She explains that she feels this way because in her case, it was more of a social thing as opposed to in the case of students staying with local families, where it was more of a comfort level, in that they get to go to their homes, and they're eating meals with their family, and therefore accessing the culture more closely.

Sharon also expressed a similar opinion. She says, "We (she and other American students) learned that it is best not to live with people from the program, it was better to live with locals. A lot of people discovered that." She says this because she feels that staying with your friends is limiting in more ways than one, in that not only is one spending time with the same people the whole day, which leads to a certain level of boredom, it also makes one complacent, and does not leave much scope to step outside one's comfort zone, interact with the locals (which, according to her, is the whole point of being in a foreign country).

Doing non-touristy things. Authenticity of tourism experience might be a much debated topic in tourism research, but these student tourists were very conscious of it at 
some level. This is sometimes also clear from their expectations from this experience. For instance, Joan wanted a real experience and an adventure, while Monica expressed a desire to experience the French culture first-hand and wanted an adventure as well.

According to Joan, meeting new people is a big part of traveling. She adds that anyone can be a tourist, but she wanted a real experience, by which she means that she wanted an insider's view of things. Having seen all the tourist oriented places with the study-abroad program, Joan was instead keen on meeting local people and hanging out with them, and having them take her around and show her places, such as their local hang-outs and restaurants. She wanted to be able to go to someone's house and see how people live, and interact with them. She was not very interested in the comfort of an organized tour with organized programs and popular tourist places, with limited or no interaction with the local population.

Joan: I feel like if you do all this touristy stuff, it's kind of like you get the experience of a tourist but like I travel and I don't want those types of experiences. I want a real experience type thing, and I have seen all this (stuff) that everyone else sees, and then go there, but I want like my one-of-a-kind experience. I always want to meet local people, and I want them to take me places, and go to their local restaurants and stuff like that. I know people that do all those Italy, France, Spain, like tourist thing. I see that (as) an older type traveler type thing. I really see all those cruise ships and stuff like that for like old people, and I'm not an old person and I just wanted adventure really. I want an experience where I can go to a place or someone's house, something like that. 
When asked about her interactions with the locals, and whether the difference in the spoken language made her uncomfortable, she says, "I didn't go there expecting them to speak to me in English", and so she approached the local people herself, using the knowledge of French that she possessed to communicate with them.

To Joan, whose main goal was to create a unique, one-of-a-kind experience for herself, touristy stuff seemed superficial and not the kind of travel experience that she craved. "I want(ed) a real experience type thing. I want(ed) like my one-of-a-kind experience." To be able to realize her expectations, she wanted to meet local people, and wanted them to take her to the local restaurants and other popular local places.

When she was in France, Amy too wanted to blend-in by avoiding any activities that the tourists seem to indulge in. However, she recalls doing a lot of touristy stuff on her trips to other countries. She felt very self-conscious while taking pictures in France although in other countries that she visited she was more comfortable doing it.

Amy: In other countries, if I didn't even speak the language to begin with, I had no shame almost. I just thought, 'Ok, I am here to see everything,' so like in Budapest, you know, we would go to all these different places, and see all these different things, and it was just like I couldn't...I was so happy to be there that I was always taking pictures, always you know, like without shame.

It's interesting to note that she mentions that countries other than France, where she didn't speak the native language, she was comfortable being perceived as a tourist while in France she preferred to blend in and appear local.

Cindy recalls that her most memorable experiences involved getting a local 
experience through spending time with local students. She says, "There were things that helped me really enjoy the local experience. It was meeting local students, actually, and just going out with them, and it wasn't so much like touristy stuff or like unique things but just hanging out with them, and like going to do all-night Karaoke.” Although she went on many organized tours put together by the program she was traveling with, which she regards as touristy stuff, she say that, "In order to travel to those places (that they toured), a lot of us decided to just go on our own, and just take the metro system on our own so we could learn it, and just go exploring on our own."

Sharon mentions, "I never considered myself a tourist to be honest with you. I adapted to the culture really quickly. I started meeting people really quickly. The first two weeks we acted as tourists." But soon after, Sharon started hanging out with locals and meeting other locals through her acquaintances, and visited their homes. She considers this the essence of her experience there. She says about the Spanish folks, "I thought it was amazing that you could just walk up to the street and meet a random person and have a blast with them for one day, and never see them again in your life. I liked that I didn't have to rely on anybody to go out."

Interacting with the locals in their own language. For the student-travelers, who were all from the United States, it was a little daunting to interact with the locals in the local language. For Sharon, Pam, Vivian, Angelina, and Monica, aside from the initial culture shock and language adjustment, their fluency in the host language helped them gain control of their situation and reach out to people effectively. Sharon wasn't really expecting to get a culture shock when she first got to Spain. Other than smoking, 
which is rampant in Spain, she found people's attitude a little hard to understand, and a little rough to adjust to. She says, "I mean you have to learn that people are not gonna talk to you if you don't talk to them first and I think that's something I wasn't expecting. And that was definitely something different." Furthermore, she mentions that Spanish people were not interested in learning or speaking in English at all, which was problematic for others who didn't speak Spanish well. For her though, with the help of her superior language skills, she could reach out to the locals herself, and adds, "I think people liked me and it wasn't bad at all." For other student-travelers, it took a while longer and it was a little harder to do so. With time, however, everyone felt more at ease and more prepared to approach the locals in their native language.

For Cindy, however, despite having ties to Hong Kong, she could never get to the point where she was completely fluent in Cantonese. She interacted with the locals in English since the locals did not have a problem speaking in English to her in most areas of the place. She says, "As for my interactions with local students, it varied. Usually it was English but you know, like, "Can you help me with my Cantonese please"? And they would. But they knew it was faster communicating with me in English. So we usually defaulted (to English) just because it was faster, which makes me sort of sad now because I could have improved my Cantonese a lot more (had she insisted on speaking Cantonese with the local students)."

Living like a local. A recurring theme in the conversations with the studenttravelers was their fascination with how the locals lived their lives on a day to day basis. There were many popular things the student-travelers wanted to see, but they also made 
every effort to blend in, and see the place through the eyes of the local people. The student-travelers talk about trying to fit-in and experience the local life by means of accessing the usual local hang-outs, indulging in local lifestyle, and trying to speak more like the locals would. Pam calls it "living like a local", where she constantly spoke to the hosts and kept an eye out for local events and festivals to experience Argentina in her own way. A good grasp of Spanish, the local language, gave her the confidence to make that happen. Some of the other things they mentioned as part of their efforts to appear local and fit-in were their tendency to avoid taking pictures, to follow a local routine, and to blend-in with the locals.

Amy felt like she was giving away her foreign origin by taking pictures. "In Paris, you always feel kind of embarrassed because you always feel like the Parisians know, like they are kind of, "Oh, you are taking pictures." I was almost embarrassed to be a tourist in Paris, like taking pictures and stuff. I guess the reason is that I wanted so badly to understand the city that I didn't want to appear like an outsider" (Amy). She adds, "I stopped taking pictures, because I didn't want to seem like a tourist. I always wanted to fit in. So in the South of France too, like we would go, and like I would try not to take pictures all the time. We would speak French, but then the minute you know, of course my accent gives it away, but the minute we started taking pictures, they're like, "Oh, they are not, they are not from here."”

In talking about how they lived like a local, the student-travelers described interactions at the most mundane places that the locals would visit as part of their everyday routine. They wanted to experience what the locals did every day as part of 
their routine. Monica wanted to experience the mundane things, like "getting a baguette on the way to class, going to a café and talking with people" in the ways that she would see them interact with each other. If for Monica it was getting a baguette on the way to class, and chatting with people at the café, for Kate, the interactions with the locals were mostly in the local market, where she would interact with people in French, the local language, even though she wasn't very fluent in it at the time. She says about her interactions, "In the market, it's nice to just immerse yourself, so I pretended to be French." She feels she was successful in blending in and getting away as a French person because, "I got some food and vegetables. I'd have my own bag, and I'd go around picking, 'Oh I like this cheese, half it (cut it in half), and just go around.'”Other studenttravelers tried to fit in by imitating the ways of the locals and by trying to interact with others the way they would see the locals interact with each other. For Amy it was visiting the local market every Sunday. She describes:

Amy: A lot of my really good experiences were at the market, where I would go every Sunday, and I would buy like fruit and vegetables and things like that. And initially I didn't understand anything they said, so I tried to give them as much money as possible to just let them give me change so I didn't know, but gradually I got more and more, and then when I would ask, I would be more brave, like asking, "un kilo de courgette (one kilogram zucchini)", instead of just pointing. And people eventually would start talking to me, and they would want to know where I was from, and this and that, and then eventually I had my favorite vendors and I only went to them. And it was really, really cool because like you 
saw kind of like a mutual, like they came to understand me a little bit, and I came to understand their language, and so I got to "access" a little bit of their world by doing so. So that was probably the most memorable time.

Monica describes a similar ritual to this in addition to her other daily routines. She says, "Sundays, I would love to just walk into town, go to the market, walk around the market, even if I didn't buy anything, but you are there, you are with the sense, the sounds, you are talking to people. I went and I bought my groceries twice a week like they (the French people) did, walked everywhere (like they do). I was never a wine person, but I tried it." She even started feeling at home and describes another favorite activity: "I liked sitting on a bench just like the locals, and observing tourists and how they seemed lost or unsure." This detachment from oneself as a tourist and regarding of other tourists as not belonging at a place is indicative of her feeling like one of the locals and of belonging there.

When asked about if she ever felt like she had blended in, Sharon says "By the end of my trip I knew exactly how to get everywhere, I knew where everything was, I knew how to tell people directions, which was nice. People would ask me for directions, which felt nice. I think I was never really looked at as an outsider. By the end of it, I felt like a local. I had integrated into the place, I knew where everything was, I knew how to get around, I knew what not to do, what to do." Monica talks about spending Christmas with her family friends in France: "It was just really nice, lots of food, good company, and by that point I had been there about four months, so my French was at a high point, so I could communicate well, it was a good atmosphere, and simply fun! I felt like I 
really was a part of it."

It was the various differences in the way locals would refer to certain things that interested Pam, and how it differed from her knowledge of the language. Both Pam and Sharon expressed the desire to expand their vocabulary by learning the colloquial tongue and interact with the locals in the ways that they understood better. Like Pam explains, "I wanted the details, and then I would be mad because I don't know every single word. Like someone could say, "Go get the 'jeans' at the store”, and there's many ways you could say it, like "there's 'pants' that I need". If you go down the street they can explain it, but I was at the level where it's like, "I want to remember that word."

Joan, Kate, Pam, Monica, Betty, Sharon, and Angelina all talk about (a) interacting with local people and making friends with them, (b) speaking like the locals and understanding the slang, (c) dressing like the locals, (d) attending local festivals, (e) hanging-out at local favorites with their local friends, and (f) participating in activities that the local people enjoy, as ways of living like a local person would. Some studenttravelers mention that speaking the language like locals was a huge help to them in their efforts to blend-in.

On the other hand, Kristin, Minh, Harry, Cindy, and Vivian, who were either not very fluent in the local language, hung out mostly with international non-local students, or did not make more effort to speak the host language lament the fact that they couldn't interact more with the local population and failed to get a closer look at the host culture and lifestyle. Minh, who had no knowledge of French before entering France, says about her interactions with the French people, "I feel may be I would have had a more 
favorable experience if I had actually talked to them (the nuns at her dorm). I would try, but I was kind of embarrassed. I wouldn't feel very comfortable. It was hard, and it did make me feel uncomfortable because I didn't know anything. And I was like, 'May be I should have studied more before going on the trip,' but I didn't."

The findings suggest very clearly that the student travelers were conscious of the underlying cultural and language related factors in the host country, and how they were different from the culture and discourse in the United States. They used different ways to define and explain their expectations related to the experience of a new culture, but it is clear that they were always mindful of cultural authenticity and had set their expectations accordingly. They all also had their own criteria to constantly evaluate it.

The next section will discuss the findings related to the student travelers' perception of the significance of language and that of the interaction with the locals in regards to their travel experience. This is covered in terms of their preparation for the travel and the advantage of being able to speak the local language, challenges with respect to language, and the significance they attach to the interaction with the hosts.

\section{Perception of Significance of the Language and Interaction with the Hosts}

Preparation. All student-tourists either knew the host language and were fluent in it to some degree, or took classes before, right after, and during the program. It is clear from their responses that they were all conscious at some level or another that it was important to understand and speak the language to experience the place fully. Harry arrived earlier than his program start date and did a crash course in Swedish to be able to get by in Sweden. The student-tourists seemed aware that for the length of time of their 
stay, they would need to have some level of knowledge of the local language since they would not always be with a group necessarily. For the student-tourists that could speak the host language, fluently or otherwise, to begin with, the discomfort of being in a foreign country, far away from the familiar sounds and smells, was relatively short-lived. It didn't take them long to make friends, or just get out and start talking to the locals, which made them feel at home right away. Pam, Cindy, Vivian, Joan, Angelina, Kristin, Amy, Sharon, and Monica all admitted to feeling comfortable as far as approaching people for help was concerned, which eased the process of settling in for them, and made them feel at home.

Challenges. Kate, Betty, Minh, and Harry felt that their limited knowledge of the host language in each of the case acted as sort of a barrier in their getting to know and bond with people they would have liked to know more about, and hang out with them. Although as time progressed, they were able to improve their language skills, the process took a long time, and deterred them at times, and made them feel lost and self-conscious. Kristin blames her inability to initiate a conversation with the local French people on her lack of knowledge of the French language. She says, "We weren't there to just take pictures. Although I wanted to hear more of the French language spoken, I wasn't able to absorb everything all the time that was being said. I regretted that I hadn't done more preparation, because I think it would have enhanced my experience more." For Amy, who picked up more language skills as time progressed, language was still a barrier.

Amy: The language was a huge part of it for me, because I was always really sensitive to the fact that they can't understand me, and I can't understand them, 
and I always felt like an outsider. It was huge for me because here I don't think about it. I go my entire day and I never think about it, but there I would think about it every time. If somebody asked me what time it was on the metro, I would be embarrassed, because like either I know I would make a mistake or like they would look at me and go like, 'Oh, she's not from here.'

She also recalls wondering about missing out on experiencing the personality of her friends whose native language was other than English:

Amy: You feel like you are only showing a piece of your personality to somebody. And of course I still think that my friends that only spoke French, like how much I missed of their personality because we didn't understand each other a hundred percent. My one friend Francesco from Italy, he only spoke French and he had this heavy Italian accent, so he would only, and he always made these little jokes and stuff, he was a funny guy. But I always got the impression that when he spoke Italian, he would speak much faster, with more force, with more enthusiasm, and I always wondered what it would be like if I could understand him. Like would I know him differently? Like would I think of him differently? Like what exactly is he saying? I wanted to understand him much more. And I thought the same even with my German friend who spoke English fully, I always wondered like what was she like speaking German, is there a part of her personality that I don't know, because she can't express it to me in English.

She feels the same about herself as well and expresses frustration at being unable to express herself sufficiently well in the local language. 


\section{Perception of significance of interaction with the host population. Monica}

says, "I wanted to become part of the (French) culture by getting to know more French people." She adds, "I didn't want to be the stereotypical student who was only hanging out with American students. I wanted to actually have French friends, and go out into the town, meet people at the store, meet people at the cafe, or talking to the waiter, doing what have you, doing what the normal locals would do, which is exactly that, they would go sit at the cafe, they would go to the store and start talking to the cashier at Monoprix."

Sharon talks about this by relating about other international or American students who did not reach out to the locals as much as she did. She says of other students from the United States who did not interact a lot with the locals that, "They stuck to themselves; their experience was very close minded. They wanted to hang out with only each other and not meet locals. I would never want an experience like they did." She adds, "I think the whole experience about going to another country is to meet locals, is to meet other people out of your comfort zone, and I don't feel like a lot of all those people did." She certainly regarded this interaction as something that defined the experience of being in a new country.

The recognition of the place that language holds and how it relates to a place's culture was evident in the way the student travelers talked about language and their discourse involving the hosts. The final guiding question, addressed in the next two sections, seeks to explore the role of language in shaping travel experiences of the student travelers.

\section{Language as a facilitator of the tourism experience}


Whether or not the student-tourists went in with an expectation to improve or master the host language, they were all always aware of the language difference, and of the significance of language in their experience of the local culture, since communication is very closely linked to a place's culture. It can even be said that culture needs communication for its sustenance. In the cases where the student-tourists were motivated to gain a better command of the host language, they tried to use it everywhere, and put themselves in positions where they would be forced to use it quite consciously.

For others, the situation forced them to rely on their language skills and gave them the opportunity to speak the local language far more than they had anticipated. The student-travelers also used their linguistic abilities to create their own experiences, through their confidence and ability to reach out to people in the countries they visited. They in turn used these skills to their utmost advantage in deriving the most from the experience. Monica says, “If I hadn't known French, I don't know how I would have survived."

A few recurring themes that came up during the analysis of the data concerned (a) opportunity for immersion in culture, (b) perceived (positive) attitude of the hosts, (c) positive experiences with the locals, (d) bonding with students over the host language, (e) attachment to the place, (f) active language barrier negotiation, (g) feeling of accomplishment, (h) ability to actively interact with the locals.

Opportunity for immersion in culture. The student-tourists felt that being able to blend-in and experience the lifestyle of the locals was very significant to their experience. Some of them even said that although they did touristic stuff, they didn't feel 
like a tourist, and felt like they belonged there. Pam mentions that being able to interact with the locals was a big part of feeling like she had blended in. Her linguistic ability gave her the confidence to venture out and make friends, and develop relationships with her host family and other locals. She made it a point to attend local festivals and go to local places to immerse herself in the place. Kate pretended to be a local at the grocery store, where she would take a bag, and buy supplies like she saw local people do.

Monica did her groceries like the locals as well. She talks about being away from home and how it affected other students. When she saw that other students were not as open to embracing and immersing themselves in the local culture, she felt that "The fact is you are not home, you have to embrace what you have in front of you, and that's what I did. I didn't miss any of our, any of the food here, I didn't miss listening to English, I didn't miss any of it, because I went there to be a part of that country and culture." She adds that she was invited a few times to small little gatherings at her French friends' homes, and she just followed their lead and tried what they were trying, and just wanted to become part of that. Amy recalls that initially she would hesitate, and just point at things while buying vegetables, but with time she became confident in her language skills and started talking to the vendors in French like any local person in a market would. Joan loved observing how people interacted with each other, and being able to understand what they were saying seemed to have helped her do that. The student tourists embraced the language and the culture, and found that immersing themselves in a culture made them understand and grasp the language more, and vice versa. 
Positive experiences with the locals. Vivian felt a lot of warmth from the locals, and this made her feel confident about speaking Japanese, although initially she wasn't very fluent in it. Their patience and understanding helped her try more. As a result, she was able to get out and talk to people, and get a closer look at the culture and the lifestyle of the place, which contributed to her overall satisfaction with her tourism experience. Joan, on the other hand, relates that the locals found it 'cute' when she spoke French but really appreciated the fact that she was trying to speak the local language. As Monica relates, "The first week, I felt a little hesitant, of course, but once I kind of just jumped into it, people were so nice about it once they see you are actually trying. French people don't really like to speak English, so the fact that I could speak French, they liked that." Monica, who sensed that the locals preferred speaking French and appreciated the effort on her part, was encouraged to use more French in her interactions with the locals during her stay in France.

Amy recalls noticing that people in France were very friendly towards her, especially when she spoke French while buying tickets. Her opinion is that the local people responded positively to the fact that she was trying to speak their language. However, in other places, for example, in Eastern Europe, especially Poland, as well as in Spain where she didn't speak the local language, people weren't as friendly. They didn't speak English, nor did they make any effort to communicate or respond if she spoke to them in English. Her perception is that when she traveled with a big group of foreigners, who were speaking languages other than the local language, it was upsetting to the locals, and was perceived as disruptive, and may have been the reason for their hostility. 
The students indulged in tourist-oriented activities from time to time, but most of them prided themselves on creating their own unique experiences by reaching out to others and exploring the places on their own. If it wasn't their first time visiting the place, they were especially more concerned with doing things that they had liked during their first visit, or doing new things based off their knowledge of the place. All the student-travelers traveled with the SJSU Study-Abroad program, which gave them access to tours organized by the program. In addition to these tours, they often traveled on their own, in the host country or outside it, on their own or with other people that they met through the program or through their interactions with the hosts. Although the studenttravelers do not necessarily use the word 'unique' to define the experience they were looking to create, they were consistent in expressing the need to step outside their comfort zone in order to utilize the opportunity to experience, and understand the country they were in to the fullest extent and in their own ways.

Joan talks about the hospitality extended to her by a French local man when she was in between apartments. When asked whether the fact that she communicated with him in French could have played a role in influencing the man's behavior, she hesitates at first, but then admits that she usually got a very favorable reaction when she spoke French. She mentions, "I remember one time when I was traveling, me and another student, and we were in between our apartments. We met some French guy at the train station and he drove us to his house and gave us food, and then we stayed at his house. It was really nice. He lived with his Dad, and he had a kid, and then he took us out to a club, and then. I was just like, "Wow, these people are really nice", and then he just like 
let us in the house and let us stay."

Amy recalled being treated nicely by a local woman at the printer shop, despite her low facility with French at the beginning of her trip, and admits that it made her feel more comfortable and positive around the locals. She also felt that as she grew more confident in talking to the locals more and using French, she felt that she received more response and interest from the local people.

Bonding with students over the host language. With students who didn't speak English, sometimes the host language was the only common grounds where the students could meet. This seemed to open up a whole new world for the students, where they made friends with students from different countries and bonded over the host language. This also enabled them to take trips to these countries where the students were from, where even if they didn't speak the local language, they had help and it made their experience very enjoyable. Angelina relates a very interesting episode with a Belgian roommate. She found herself interacting with her solely in Spanish, and given her experience with the city where very few people, if at all, spoke English, she assumed that her roommate didn't know English. She explains, "I didn't even find out until two weeks later that she (her Belgian roommate) spoke English. I had no idea. I found out because she was speaking to my other roommate in English, but she never told me that, because she wanted me to depend on my Spanish, and so that was a huge advantage for me. I'm actually really glad I didn't find that out, but even after I found that out, we continued speaking in Spanish together."

Monica talks about her friend who she got close with as a result of their common 
language, which was French. She says, "One friend, I have a really good friend now. She's from the island of 'La Réunion', (and) it's French. And because I could speak French, it was very helpful. She spoke some English, but we bonded over the fact that she was learning English, and I was learning French; we would help each other with homework; we would sit in the kitchen, and we'd just chat over things, helping each other, and introducing each other, like, "Oh, give me a show in English", I was like, "Give me a (TV) show in French, let's compare notes". And in that sense it was definitely helpful."

Although they used English to begin with, Amy says about her relationship with other international students:

Amy: Everybody bonds really quickly. After the first two or three weeks, it was like I almost didn't feel anymore like, 'I am an American, and this is a Brazilian, and that,' we all felt just like we were in this together, like a family. But I learned a lot about their culture, and I think they learned about mine.

She adds about her Italian friends:

Amy: They only spoke French or Italian. So we would speak in French then. And then of course it's funny, because it's easy to speak with somebody in like a language that's not their mother tongue if you both are speaking it. Because like neither one of you understands it perfectly, so it's easier.

Sharon says about Spanish skills: “(I'm) completely fluent. It's my first language, so it worked out perfectly for me." Her fluency in Spanish, in addition to her outgoing personality, helped her in her communication with the locals and helped her reach out to 
them without the slightest hesitation. She says of the other international students who weren't as fluent as she was in Spanish, "I know for some people it wasn't as easy to communicate, for some of the Americans that really had Spanish as their second language, I know for them it was a barrier to have the lack of communication, have that confidence to be able to talk to anybody. I have always had that confidence; my Spanish is at a really excellent level. If anything, my Spanish improved as I was there. I went to a more sophisticated level. So that was only an improvement, if anything (for me)." Realizing this, she tried to help other students there in picking up good Spanish skills and fluency in the language by insisting that they speak as much Spanish with each other at home as possible.

Attachment to the place. Coming back was hard for everyone, but for Angelina and Monica there was a realization that they will never be able to recreate the life they had there once they got back. There was almost always a desire to go back someday. "It was horrible coming back. It's just a great country, it's a great experience; people are great. The people I got to meet were just amazing and it was very unfortunate to have to come back." (Sharon)

Another interesting finding was how the student-tourists seemed to regard the place where they were as their home away from home. While in that place, they would make every effort to blend in and learn the host language, but when traveled outside, they made very little effort to prepare themselves in terms of the language. For instance, Sharon did not make any effort to communicate in French or German when she was in France and Germany respectively. Amy learned a couple common words in Polish and 
Spanish, and Angelina did the same in French and German, but neither went out of their ways to communicate with the hosts, especially because they were visiting these places for a short amount of time.

Active language barrier negotiation. The student-tourists, especially the one that were fluent or close to being fluent in the local language, found a variety of ways to get around the language barrier. They would take the initiative and speak the host language, ask others to repeat or speak slowly to be able to understand rather than expecting them or asking them to speak English, (except Harry/Minh who spoke very little Swedish/French and needed to resort to English). Angelina and Joan would try everything to make communication happen. Using hand gestures, pointing at things they wanted at restaurants, or speaking a few words of the local language to break the ice were things that they actively tried.

However, it wasn't always easy to get by without knowledge of the local language as Sharon puts it: "Being in France, trying to communicate with a young man. Didn't work out! At no point did we really understand each other. (On) New Year's Eve, I kind of met this person, and if it weren't for his friend, me and him would have never spoken. We had nothing in (common), we couldn't speak each other's language”. Although Sharon did her study-abroad in Spain, and is fluent in Spanish, she did not speak French at all which hindered communication despite her outgoing personality. However, the (a) length of stay, and (b) use of non-verbal cues helped the student-travelers negotiate the language barriers more effectively.

Length of stay. Betty feels that her short trips to places where people didn't speak 
much English was not significantly affected by the language difference since she wasn't at those places long enough to really interact with anyone outside of the tourism or hospitality industry service providers. She adds that traveling with others who either spoke the local languages or had prior knowledge of the visited place helped her feel safer and not be negatively affected by the difference in the spoken language with the locals. Kristin visited Belgium and Copenhagen, and felt the same way.

Non-verbal cues. With other student-travelers, regardless of whether they spent a lot of time in the host countries or not, non-verbal cues and knowledge of some common words would come in handy. Sometimes, knowledge of a different but somewhat similar language would come to the rescue, like for Monica, who tried to get by in Italy by mixing her French and Spanish. Amy, who did her study-abroad in France, says, "When I did speak French with people, I noticed that even then like a lot of body language could just fix the problem."

In Germany, where she didn't speak the language at all, Angelina would point at things, for instance, when ordering food in coffee shops. She says, "I thought, 'Ok, whatever, I am just going to point at the picture, and I will just get whatever is in the picture!"'Also, "when we were in Paris, we had to just like point on the menu!" However, she was always aware of the fact that language difference interfered with her interactions with the local people. She says, "Whenever I traveled, I would get into that country, I'd be like, "Wow, I wish I had taken a semester of this language", like all I wanted was to be able to speak that language." I would get frustrated, like when I was in Paris, I thought, "Wow, I wish I had paid more attention to my French classes", because I 
could have probably used more, and so that's the part that's frustrating, but I mean we got by as best as we could!"

Feeling of accomplishment. For Amy, traveling abroad was associated with some discomfort, since she was leaving her family and home for an extended period of time. At the same time, it forced her to be in her element, become more independent and worldly, and was important to build character. She says, "I was expecting to kind of grow as a person. That was why I did it. I wanted to grow into somebody more independent, a little more worldly, more understanding. When I came back, I really understood the world a lot better" Most student-tourists agree with this line of thinking, and felt that they expected to know and understand more as a person once they traveled, as a result of being exposed to different cultures and ways of living.

Kate's expectations included personal growth, and discovering the aesthetics of the French culture (coming back quotes). Sharon, Angelina and almost everyone else talks about how these experiences changed them as a person and helped them grow.

Sharon: I am a lot more outgoing; I am a lot more open-minded. I want to travel the world a lot more. A lot more!! I am a lot more free; I'm a lot more independent. A lot more independent than I used to be. I know that I can make it on my own. I wish I could go back. That's pretty much it. I wish I could go back!

With time, the students not only develop stronger language skills, but also a keen insight into the culture of the place, and feel more independent because of that. The confidence in themselves that they can take care of themselves and deal with unforeseen 
situations was also one of the things they noticed about themselves. The experience seemed to change them as a person where they feel more tolerant and understanding as well as appreciative of others who don't speak English as well as they do back home, something they feel very good about. Being able to deal with language barrier, whether in classrooms or outside when interacting with the locals, gave the student-travelers confidence to survive in an alien country. In addition, the student-travelers were able to use their language skills in many different ways, like Angelina, who enjoyed being able to take her family around Murcia in Spain, and acting as the host, being comfortable asking people for directions, and being able to speak Spanish fluently with the locals.

In some cases, the initial few weeks were difficult as far as communication with the locals was concerned. However, with time, the student-travelers were able to hold conversations with the locals in the local language more effectively, which gave them a tremendous sense of accomplishment.

Ability to actively interact with the locals. Meeting new people and experiencing a new culture was high on the list of expectations the student-tourists had from their experience at the study-abroad program sites, apart from learning the language in most cases. The student-tourists claimed that they went to the countries without any expectations that the locals would speak to them in English, but knowing that they wanted to meet new people, and interact with them. They thus made every effort to visit places where they would come in touch with the locals, even if sometimes it meant just taking a walk and talking to random people on the street, as Sharon puts it, or splitting from the group where the default language would be English. 
Sharon says, "I think the whole experience about going to another country is to meet locals; to meet other people out of your comfort zone." She recalls her random interactions with the locals leading to lasting bonds, and sometimes even meeting other locals and going to their houses as a result of these friendships. It probably ties back to her comfort level with the language since she chose to go to Spain because she knew she would be comfortable with the language since Spanish is her first language. She explains, "It was just a random person I met on the street. We ended up having a couple drinks, going to a couple discotheques, as she'd met a couple of other people, and we just all ended up together. It was a great time; that was one of my really close friends that I just randomly met. She became a really good friend.” Meeting new people as a result of the confidence that came from speaking the locals' language gave Sharon the opportunity to build lasting relationships and meeting more people through the bonds she made in Spain.

Angelina mentions that the knowledge that she had the skills to converse with the locals in their language (Spanish) encouraged her to reach out to them. She made sure that she was warm and personable in her interactions with the locals, who, according to her, seemed to love personal interaction. She says, "It's really meaningful, and you that was just another way to connect with the local people, even though it was just one time, it was one conversation." For Angelina, the opportunities were a good way to reinforce her language skills and put them to use, deriving a sense of accomplishment from it. She says, "So just little conversations that I'd have, I actually really enjoyed that, and part of it was because I knew that I "could" communicate with them, (and) I would take advantage 
of those, because I knew it was an opportunity to practice."

Joan is pretty certain that her desire for a real and more satisfactory experience would have been satisfied if she had traveled by herself once she arrived in France. She says, "I think it probably would have been better if I was by myself. When you are by yourself, it forces you to talk to the people." She feels that while traveling, she could have met more people who would have kept her company on the trips she took, but she wouldn't have been forced to stay with the group, and could have experienced more interaction with local people.

\section{Language as an inhibitor of the desired travel experience}

Student-travelers, as part of the study-abroad program, have to constantly engage in interactions with the professors, and other students, local, American, or foreign. The reasonable length of time of their stay in the foreign country requires them to speak to locals on several occasions as well. The lack of knowledge of the host language affects many of these interactions, and make the students a little self-conscious and uncomfortable, affecting their tourism experience negatively in some cases. When students are determined to learn the host language, there is an active effort going in constantly since their attitude differs somewhat from someone who is there just to escape routine or seek change through travel. In this case, it is centered more on learning and achievement. However, several language-oriented factors were discussed by the studenttravelers as reasons for their hesitation in feeling comfortable in the foreign country.

Culture shock and language adjusting. All the student tourists go through a phase of language adjusting and culture shock since it is a new setting. But for some, 
especially if the pace of their learning the language is slow, it makes them feel lost during the length of their stay. While others recover from the initial shock, get involved with other students, form friendships, and try new things, some of the students weren't able to form any good friendships, or try new things since they weren't able to adjust that well.

Amy says she thought a lot about the language aspect when she decided to travel to France. She admits that she was acutely aware of it the whole time she was there; especially that being able to express oneself in one's mother tongue is so much easier than expressing oneself in a foreign language. She goes on to describe it metaphorically as, "You feel like you are like swimming but like your arms are tied behind your back, and people don't understand you". Even when increased fluency in the host language over time, some student-tourists felt that they couldn't let their personalities show because it wasn't their first language. Amy says, "You feel like you are only showing a piece of your personality to somebody." She also felt that she probably missed part of her other friends' personalities too, if their native tongue was different than the host language, which was the common language between them.

The student-tourists could sometimes feel the frustration of not being able to be as fluent and perfect as they wanted to be, and not being able to do their transactions as smoothly as they could have in the United States. Harry felt left out and couldn't hang out with Swedish students or students who didn't speak English but knew how to speak Swedish, since he didn't have that kind of facility with the language. Amy and Vivian both experienced some discomfort occasionally when they took time to understand what some of the locals were telling them, especially if any unfamiliar vocabulary had been 
used. If it took them long to grasp it, and if they would sense that people around them or people they were dealing with looked impatient, it would increase their discomfort, leading to less active effort on their part and the frustration that comes from the inability to ask questions and participate in the daily life activities like everyone else did. Amy says about this, "You feel like an outsider, like you are behind a piece of glass, and you can see everything, but you are not participating, and there is no way for you to participate, so then there's no way for you to understand it as a result."

Sharon noted that, "Spanish people are a little more closed off; they are a little more reserved still. They're more into their own groups because a lot of the people in Spain refuse to learn English." Since Spanish is Sharon's first language, she was able to look past this and still have a healthy amount of interaction with the locals. But other student-travelers, who weren't as fluent, would stick to their English speaking friends and groups, limiting their access to the local population.

Negative experiences with the hosts. When the student-tourists interacted with local people, sometimes their interpretation of the way the hosts were treating them would translate to a bad experience. With Joan, even when she didn't understand exactly what the person was saying to her, the fact that it sounded harsh and made her uncomfortable and unwilling to interact with the locals at the place. Amy was very comfortable in France since she spoke French well, but when she went on a weekend trip to Poland, the behavior of the Polish people at the train station put her off and discouraged her from initiating any conversation on her own.

Harry had a similar experience in Sweden where he felt left out since he couldn't 
communicate well in Swedish with the local students, or other international students who didn’t speak English. In these instances, there was always a feeling of isolation and hostility associated with the behavior of locals in the countries visited. This was sometimes directed towards the use of English language and sometimes towards the student-traveler who could not speak the local language as the locals did. Monica mentions an episode related to her friend where she felt discouraged after receiving unnecessary criticism from a French local regarding her accent and inability to be naturally fluent in French. Monica says about her: "That's where you hit the roadblock where you don't then necessarily want to be interacting with the locals anymore. And so those students then were the ones who would interact more within their dorm, and people who spoke their own language."

Interest of locals, and local or international students in learning English. A lot of times, the student-tourists encountered people, be it locals, or other international students, who wanted to improve their English skills, and so expected the student-tourists to communicate with them in English. The student-tourists felt cheated by this behavior since they had traveled all the way there in order to learn the language and interact with the hosts in their own language. This could also be seen as their being deprived of an authentic experience in the country. Amy mentions:

In the beginning, it was always English, but then one of my roommates insisted on speaking English, so as my French got better, she would still only talk to me in English, very much in, like not a lot in French, and the other one was so nice and she insisted on French always, no matter what. So I learned a lot thanks to her, 
but the other one was always talking to me in English. She had good English, but she didn't want to forget it, because she was back. And so she always viewed it as an opportunity to practice with me. In her case, I often felt like taken advantage of, like I am here to learn your language but then.

One of the several reasons for Amy's decision to travel with the study-abroad program was the rich opportunity to work on her French language skills through communication with the local population. Thus, it was frustrating for her not to receive the help of her roommate in her efforts to improve her language skills and it took away from her travel experience.

\section{Confinement to touristic activities, bigger cities or larger groups. Although}

they wanted to explore new things and go to places that were more remote and symbolic of the culture (and not too modern), most of the students went to popular big cities when they traveled to other countries from their study-abroad program site. This was true for Angelina, who traveled to Brussels, Paris, and Berlin.

For the students who lacked the basic fluency in the host country itself, lack of language skills would sometimes prevent them from venturing out to places where English was not spoken. Even in the host country, where most of them were able to make friends and felt comfortable, they would confine themselves to the more tourist-oriented activities and sites. Amy further adds about traveling in a group:

It helps, because then you always have two sets of ears, like in the Czech Republic, if we didn't understand what they said to us. Even then at least you have other people who are also there, who can kinda like help you like, 'Oh! Did they 
just ask for this or what did they want?' Plus (there's) safety in numbers. You felt a little more safe.

Thus, for some student-travelers, students who could actively negotiate language barrier, different spoken language at the toured destination was not a substantial obstacle. However, for other students like Kristin and Minh, traveling with someone who was fluent in the local language or with a group where there is safety in numbers was an equally appealing solution.

\section{Summary}

An analysis of the interviews revealed that the student-travelers were acutely aware of their motivations to travel and had varied expectations of their travel experience. They spoke about culture and authenticity in different ways. Some of them spoke about lifestyle, while others mentioned food and architecture. However, they all felt that interaction (day-to-day or general) between people was the most important component of the culture of a country. Furthermore, they clearly felt the importance of language in regards to communication and interaction between people, and that language holds a very significant place in the experience of and participation in, the culture of a place. Whereas the length of their stay motivated as well as enabled them to get a closer look at the local culture and way of living, their knowledge of the local language enhanced their insight into the lives of the locals. On the other hand, the lack of knowledge of or fluency in the local language hindered this process of digging a little deeper to get a closer look at the local lifestyle.

Pam found that the best part of her visit was when someone thought she was from 
Argentina, because her accent was so much like that of the locals. The facility with language enabled the student-tourists to create their own one-of-a-kind unique experiences by stepping outside their comfort zone and interacting with strangers, having random conversations, and going to new places. There was a lot of risk negotiation seen in the travel experiences they narrated, probably as a result of feeling comfortable enough with the language. As a result, they thought themselves capable of trying new things and going to places that weren't as popular as the main cities and where English wasn't spoken generally. These students qualified their experiences as being more than they had expected them to be, and seemed to be very satisfied with the experiences they had had.

Where student travelers were looking for some kind of escape from boredom, or change from the routine, or having new experiences, satisfaction was still achieved, since the goals were different. However, the realization that they would have been able to use the opportunity and time to interact with the locals more, and bond with other international students, or make local friends, caused them some regret, and a determination to prepare well in terms of the knowledge of the place's language before they traveled.

The interaction with the local population was certainly affected by the studenttraveler's ability to speak the local language. Whether this was true for certain parts of the country being visited, or throughout the country, it interfered with their overall experience and in spite of being able to recall many memorable experiences, they collectively feel that lack of fluency in the host language takes away their confidence to express themselves fully and reach out more to the local people. This in turn affects their 
satisfaction with their experience of the culture of the place. Student-travelers that were fluent in the local language were able to step outside their comfort zone and experience the local life fully and seemed to have very rich and fulfilling experiences. The studenttravelers who could not reach out to the local people as a result of lack of fluency in the local language tried to negotiate the language barrier in various different ways but often experienced frustration and isolation arising from their inability to express themselves fully. 


\section{Chapter V}

\section{Discussion and Conclusion}

This section reflects back upon the original purpose of this research study: exploration of the role that language plays in shaping international cultural tourism experience of student-travelers. The main guiding questions that drove the study were related tothe process of tourism, which begins with tourist motivations affecting the decision to travel, and involves various factors that affect the final tourism experience. Previous research suggests that there are several factors that may change tourist motivations during the travel, and which also affect the travel experience in a big way (Oppermann, 1995). The manner, in which language interacts with these initial and intermediate motivations, as well the role it plays during the travel process in defining the tourism experience, is the focus of this research. The aim is to also study this in regards to the significance of interaction with the host population at the country being visited. This chapter is aimed toward discussing the findings of this research study within the framework of the main guiding questions, which were:

- What travel motivations drive the subjects to decide in favor of traveling to the particular destination that they travel to?

- What are the different ways in which the tourists talk about 'cultural authenticity'?

- What are some of the ways in which these experiences shaped by the difference in the language spoken at the destination being similar to or different from their spoken language?

- What significance do the student travelers assign to the experience of interaction with 
the locals and the role of language in their perceived experiences?

In addition the primary study purpose of exploring the role of language in the international cultural tourism experience, this research seeks to close research gaps related to the study of languages by tourists, or tourist language-learning, and its significance to tourism experience. Phipps (2006) states that although there is literature in the study of language pedagogy and language acquisition, the context of languages learned for and by tourists is practically untouched. This study also supports the stand that Phipps (2006) takes in emphasizing that tourism, being the multilingual and intercultural phenomenon and the world's largest industry, that tourist language-learning deserves its own place in tourism and linguistic literature and research. Until recently, the little research that has involved the interplay between tourism and language has been focused on the role of English in tourism (Fox, 2008), for example Cohen and Cooper's (1985) research on 'language brokerage' and that of others in terms of English promoting a global lifestyle (Thurlow and Jaworski, 2003). However, in the realm of international tourism, there is a merging of lifestyles and cultures, as well as of language. Despite the elevated status that English enjoys in the tourism industry, there is evidence of the increasing desire on the part of tourists to interact with the hosts in the local language. It is felt that there is a need for the study of the role that spoken languages at the destinations play in affecting the tourism experience. Finally, this study explores the relationships between travel motivations, language fluency, and interaction with the hosts, and their effect on the tourism experience of cultural authenticity, by studying a unique segment of tourists, namely international student-travelers. 
This chapter will revisit the guiding questions of the study and use them as the framework for reporting the connection between cultural authenticity in the domain of international tourism, and the spoken language as well as interaction with the hosts at a destination. Like reported earlier, data was obtained from the analysis of semi-structured, qualitative interviews with 13 San Jose State University students who traveled with the University's study-abroad programs for durations ranging from one month to one year. This sample was found to exhibit various travel motivations as well as levels of fluency in the host language, resulting in different degrees of interaction with the hosts and participation in the visited country's culture. The process of their travel that starts with motivations and ends with their tourism experience will be elaborately discussed in terms of factors such as language and discourse.

\section{Question One: What travel motivations drive the subjects?}

In assessing and modeling the behavioral process for tourists incorporating motivation, expectation, and attitude, Hsu, Cai, and Li (2010) explain, "Motivation represents one's psychological needs to pursue a goal state (p. 291)." They do note, however, that expectation, defined as a belief that a particular action will lead to some defined outcome, is a necessary condition for the pursuit of such a goal. In addition, travel motivations and expectations define and are in turn defined by the attitude of the tourist. The thought processes involved in forming expectations and identifying motivations are complex and varied. They are also dynamic, and therefore will change with time, even during the travel itself. These interrelationships, rather than a separate, sequential progression among the different components of the travel process, became 
more apparent as this subject is explored in the current research.

The student-travelers reported various motivations to travel with the study-abroad program. Among these, the primary motivations included need for change from everyday routine, experiencing a new place, meeting new people, second-language acquisition through cultural immersion, and learning about a new culture. Traveling with a structured program was mostly undertaken for reasons of cost and time, but at times it also provided the security and comfort that comes from traveling with a group, especially to an alien country. As data indicates, for most student-travelers, the choice of the destination was governed by their fluency in, and/or interest in learning the local language, giving them a sense of security and ability to meet new people without experiencing a language barrier. For some student-travelers, the decision was based on the choices that were available to them, which, in some cases, were limited by their lack of knowledge of the languages spoken at different destinations.

The interest in the language of the visited country, however, was evident throughout the research study. The student-travelers were all invested in learning the local language and acquiring better language skills throughout the travel process, with some doing it more actively than others. While most of the student-travelers traveled with initial motivations involving language acquisition and/or mastery, for others the initial travel motivations underwent change to include language, after arriving at the destination (Pearce, 1993), and were affected by their experiences at the destination involving other people there.

Dornyei (1990) cites McDonough (1981) in saying that one of the reasons that 
people acquire a second language is for wider social contact. Since 'meeting new people' was a recurring theme as well, it is evident that the lack of linguistic skills pertaining to the local language was apparent when it existed, and was seen as an obstacle in meeting the expectation of a wider social contact. Additionally, it was widely observed that the ability to create a unique and real experience and to blend in with the locals were both high on the list of the student travelers. All of these necessitated communicating closely with the locals. Learning and speaking the local language was seen in all the cases as necessary for this much desired discourse and an appropriate way to achieve the abovementioned goals. Hence, both travel motivations and expectations, at the beginning as well as while travel progressed, appear to significantly involve the local language and the student-travelers' comfort and fluency in using it.

\section{Question two: What are the different ways to talk about "cultural authenticity"?}

Cultural authenticity is an abstract term that has always been a source of contention among researchers. In accordance with Wang's (1991) proposed construct of existential authenticity, this study was focused on touristic activity (and not toured objects) that lends value to the authenticity of the experience for the tourist, arising from the points of views, beliefs, perspectives, or powers of the travelers themselves. These activities thus involve personal and inter-subjective feelings as well as meaning-making by tourists. Mkono (2012) insists that as long as there is a conscious effort on the tourists' part to evaluate authenticity of experiences by whatever criteria they choose to apply, authenticity remains a legitimate concept firmly embedded in the development of tourism theory. Thus, the effort is to dig deeper into the data and extract the various ways 
in which student-travelers talk about a place's culture and experiencing it in its purest, most untainted form. This, in turn, will provide clues to the perception of cultural authenticity in the student-travelers' minds, even without the explicit usage of the term itself by the student-travelers. Language was mentioned explicitly in various ways, including discourse involving the locals as well as engagement in local life through mimicking of local interactions by the student travelers.

Language and discourse. The way people interact with each other, in addition to their lifestyle, was one of the recurring themes that reflected the perception of cultural authenticity and experience of the culture of the place for student-travelers. The way language worked and the sense of humor of people (Amy), the significance of interacting with people (Monica), the ways in which people interacted with each other (Joan), and participation in the local life based on tips acquired through interactions with locals (Pam) were all regarded as ways in which the student-travelers perceived the culture of a place. Fluency in the local language was the biggest facilitator of experiencing the culture as desired in each of these cases.

The concept of existential authenticity involves personal or inter-subjective feelings activated by the liminal process of tourist activities (Wang, 1999). In this regard, the student-travelers mentioned various means to enable them to experience the true culture of the place, and the authentic lifestyle of the locals. To be able to behave like locals and experience the culture by mimicking their lifestyles, the student-travelers were mindful of their fluency in the local language (Amy \& Kate), slang used at the place (Monica \& Cindy), and the difference in accents as well as vocabulary they had acquired 
in school and through books in contrast to the terminology utilized by the locals (Pam \& Sharon).

Language was thus regarded as a primary component of culture and key to the experience of cultural authenticity at the place. In addition to this, interaction with the locals was considered a necessary condition for an authentic tourism experience. In some cases, the student travelers even regarded staying with a local family as the most effective way to immerse themselves in the culture thereby leading to a more authentic experience. Building on their knowledge of the local language, and through discourse involving the locals, the student-travelers were keen on achieving a feeling of belonging in the host country. They considered living just as a local would live in ascertain manner to stop feeling like a tourist and detach themselves from their tourist identity in order to blend in with the local population.

In the case where a student-traveler traveled to a more tourist-oriented destination, like a city, they were able to speak English with fellow students and locals, which made it easier for them to communicate with people. However, some lament the fact that they were not put in situations where they could acquire more language skills through forced usage of the local language. It was seen that they regarded these experiences as those of an outsider, and always felt like they were standing on the periphery, and never got an opportunity to fit in with the locals and get a closer look at their culture or their lives.

For student-travelers that were fluent or close to fluent in the local language, being in cities where the locals did not speak English very well, or insisting on speaking the local language, allowed them to address the language barrier successfully. For 
Angelina, being in Murcia, Spain, forced her to depend heavily on her Spanish to get by in the city. She regarded this particular situation as the reason for a massive improvement in her Spanish speaking skills. Monica had a similar experience in France, where she sensed that the locals did not like it when people spoke English, and this encouraged her to speak French more when communication with the locals. This in turn enabled these student-travelers to form meaning relationships and bond effectively with the locals and other international students by means of the local language.

In other cases, students felt that they were not able to communicate as well with others as they wanted to communicate with (Harry, Kate, and Minh) because of the language barrier. This frustration regarding their inability to mingle with the local population (hosts) is a strong indicator of their belief that they desired an experience which involved discourse with the locals in the local language to bond with them, which in their case they weren't able to carry out successfully. There was also a tacit understanding in the minds of all student-travelers that they were in a foreign country, and should therefore try to speak the local language instead of expecting anyone to necessarily speak English to them. However, they were able to keep to their respective groups within which everyone spoke English, but this clearly prevented them from experiencing the place in its authentic form, in other words, through and with, the locals. Kate talked about the language barrier that she faced with a French person she met on her study-abroad trip to France. She could not bond with this person since they could not communicate very well due to the absence of a common language between them that they were both fluent in. She also mentioned that she stayed with a fellow American, and 
communicated in English with her roommate and other friends. As a result, her interactions in French (the local language) were not very frequent or on-going. They were limited to the ones she had with the vendors at a local market that she visited once a week for groceries. Cindy, who traveled to Hong Kong, also mentioned defaulting to English with her group of friends, which they were all comfortable speaking. She regretted not trying to learn more Cantonese through her interactions with the locals. Amy mentioned feeling like an outsider because of lack of French language skills, and not being able to fully express everything that she desired in her interactions with the locals and not being able to blend-in as much as she would have liked.

The desire that the student-travelers expressed with regards to experiencing the place from the perspective of a local is discussed more in the next section.

Living like a local. The concept of authenticity is a very subjective and personal one. It depends largely on the criteria used by the tourists (Mkono, 2012) to judge their experiences as authentic or unauthentic. The findings of this research study indicate that the student-travelers regarded doing non-touristy, more local activities, and following a routine that they would see the local people follow as crucial elements of their experience of the place in its authentic form. In this sense, the student-travelers regarded spending time with the locals, and interacting with them as they witnessed them interact with each other, as definite ways to feel like locals themselves and blend-in with the local population. In other words, this was how they attempted to blend in and create an authentic experience for themselves. In some instances, they even mimicked the way the locals dressed to fit in with them more. Monica relates her time spent with a host family 
during Christmas as the time when she finally felt like she was part of the place. She says this because she was comfortable spending time with the locals by that time, and had gained enough fluency to hold a conversation in the local language with the host family.

The student-travelers who were already fluent in the host language strongly suggested that being able to communicate with the hosts at local places such as the market, grocery stores, or local hang-out places and festivals gave them a feeling of belonging there. It also made their experience very unique and comfortable. As mentioned previously, for others, who weren't as fluent in the local language, there was a feeling of being left out, and of standing on the periphery, and always experiencing the place and the culture with the eyes of an outsider.

\section{Question three: How significant is language and interaction with the locals?}

Meeting new people was a very strong motivation as indicated by the data collected during interviews with the student-travelers. The student travelers were almost always conscious that language was a tool that they could use to interact with new people, and to form new relationships. Furthermore, they all regarded interaction with the local population and the ability or inability to speak the local language as major factors in their travel experience.

As the data suggests, English was not always an option if the student travelers desired interaction with the locals. For some student-travelers, who stayed in cities that weren't used to tourists, the only option was to stick with others who spoke English, and forgo the ever-present opportunity to meet new people and to get to know the locals and their culture a little better. There was clearly a feeling of frustration among the student- 
travelers arising from the experience of a language barrier which prevented them from making more connections with others at the study-abroad location. Harry talks about the introverted nature of Swedish people, and that lack of language skills on his part created a huge barrier for him and prevented him from making any local friends. Even where other international students were concerned, he was limited to talking to people who knew English, as a result of which he was able to interact with very few people in Oopsala, Sweden, where he did his study-abroad for a full academic year.

Student-travelers that were able to interact freely with the locals as a result of their superior language skills, or as a result of staying at the place for a longer duration that aided acquisition of stronger language skills, were always more at ease at the place, and in most cases stopped considering themselves as tourists anymore. In their eyes, they were living just like the locals at the host destination, and experienced a sense of belonging. This was crucial to the travel experience they desired.

The student-travelers with the greatest levels of fluency in the host language regarded their travel experiences as positive, and stressed repeatedly on the significance of the many relationships they had built and on the amount of learning they had achieved during the length of their stay in the host country. These relationships were both with the hosts as well as other international students at the destination. Monica and Angelina talk about the relationships they developed with other international or local students as well as the memorable time they spent with the locals as a result of their fluency in the local language at their respective study-abroad locations. Pam tried to bond with the family she was staying with as well as her teachers. She wanted to learn as much as she could in 
class, but to also form connections that would enable her to go back and live in Argentina someday if she wished.

The student-travelers make it explicitly clear, without an exception, that knowledge of the local language was of prime importance to their experience of the place they were doing their study-abroad at, and that they were constantly aware of its significance. For those that were fluent in the local language, after an initial culture shock, things went smoothly and language barrier did not surface unless they took short trips to other countries where they did not speak the local language. In those cases, however, the short duration of the stay made it possible for them to get by without getting too close to the locals and their culture. They were, however, still very active in negotiating the language barrier since their experience with the local population through their study-abroad program had made them more confident in approaching and bonding with people. The student-travelers, who weren't very fluent to begin with, or at a very basic level as far as the local language was concerned, were not as successful as getting past the language barrier and adjusting to the local culture. Kate, Betty, and Minh were able to order food and drinks in restaurants, but hesitated as far as approaching locals in general was concerned because they were unable to negotiate the language barrier as well as others who were more confident with their language skills.

\section{Question Four: How language shapes the tourism experience?}

Intercultural communication is regarded as the quintessential component of the modern world society, and is necessary for harmonious engagement between people and languages, whether in a multicultural, multilingual nation state, or within the tourism 
context (Phipps, 2006). Language is the carrier of this communication, and the necessary tool for its sustenance. The results of this research study clearly indicate that language is a very significant factor in how the student-travelers experience a new, foreign country, and their level of fluency in the local language certainly influenced the quality of their overall travel experience.

Increased engagement with the locals and other international students was desired by all student-travelers who wanted to meet new people as part of their travel experience. However, each student traveler's experience varied, based on several language related factors. Their fluency in the local language enabled them to fit in with the local population and experience the local culture very closely. If the common language between the student travelers and other international students was the local language, their facility with the local language helped them in forming strong bonds with the other international students who didn't speak English fluently. It also encouraged a sense of camaraderie, especially since the student travelers found others who were aiming for similar goals as they were in terms of language skills. Amy, Angelina \& Monica all talked about their experiences with international students from different parts of the world, such as Réunion, Sweden, Chile, Costa Rica, and Russia etc. The fact that they could communicate with these people in the local language and help each other improve their language skills enabled them to find common grounds for interaction.

The findings also suggest that fluency in English gave them the student-travelers opportunity for mutual exchange as well. The student travelers talked about trading their knowledge of English, and helping the locals or other international students with their 
English, in return for help with their language skills in regards to the local language. In some cases though, they also felt some misgivings about helping others with their English since it interfered with their acquisition of better local language skills. For instance, both Amy and Cindy, felt that they could have learned more and gained more fluency in the local language, which was prevented by the interest of the locals in learning and practicing English with the two student-travelers at their respective study-abroad locations.

Fluency in the local language also gave the student travelers the confidence to approach local people freely, and the warmth they felt from the locals further encouraged them to work on their language skills. It should be noted, however, that the student travelers were more conscious of language in the country where they did their study abroad program. This is most likely related to the length of their stay there, which necessitated close interaction with the locals. If they traveled to other countries, in spite of being aware of the cultural difference and the language barrier, it did not dilute their experience greatly because they engaged more in touristic activities and interaction with the service providers, not locals. They were comfortable being perceived as tourists in other parts of their study-abroad country, or in other countries, but insisted on fitting in at the place where they were staying with the study abroad program (Kate, Amy, Pam, Angelina \& Sharon). The research findings indicate that the ability to speak the local language gave them the means to fit in by enabling them to mingle with the locals and visit local places confidently, trusting that their linguistic capabilities would help them communicate with the locals comfortably. 
The lack of fluency in the local language, on the other hand, interfered greatly with the student travelers' travel experience. It gave them a sense of isolation and they lacked the confidence to mingle with the locals and other students who didn't speak English very well. These student travelers struggled to express themselves and form bonds outside of their immediate group. Data suggests that they were, more often than not, forced to confine themselves to touristic activities, and were not able to get a closer look at the local lifestyle and culture. Kate, Harry, Kristin, and Minh possessed very basic language skills, and were not able to interact closely with the locals they came in contact with. They stated very clearly that their lack of language skills prevented them from getting to know the local people better, something they regretted deeply. Thus, they attributed this failure to capitalize on the opportunity to understand the local culture better and interact with the host population more to the language barrier they experienced at the host destination. The tremendous frustration they experienced as a result was coupled with a lack of sense of accomplishment since they realized that if they spoke the local language more, or made efforts to learn it more while in the foreign country, their travel experience would have been richer and more complete.

\section{Limitations}

This qualitative research study, focused on exploring the role that language plays in shaping the cultural tourism experience in the international tourism context, has several obvious limitations with respect to the reliability and validity of findings. Unlike quantitative research, its very subjective nature makes it impossible to generalize the findings. However, the exploratory intent of this study automatically precludes 
generalization beyond this specific group of interviewees. The study does not claim that language is equally significant to the experience of all tourists in general, and care has been taken to relate the findings specifically to the sample that was studied. Further, since this is a qualitative study, utmost care was taken to filter researcher bias and introduce objectivity.

The sample of student travelers interviewed for this study consisted of 12 females and 1 male co-researcher. The lack of gender diversity, and the fact that they are all native English speakers, may have skewed the findings due to the homogenous nature of most of the sample group. However, not much can be said about the effect of gender on the actual findings because of lack of relevant data necessary to make that comparison. In addition to this, the sample group consisted of student travelers from the state of California that were willing to share their experiences. This further limits the research findings since not enough is known about the mindset or experiences of student-travelers from other states in the United States, or even other countries, or the ones that did not come forward to be interviewed. The sample also self-selected students with an interest in traveling to a non-English speaking country and several were taking language classes. This likely biases the sample toward student travelers who have an inclination and interest toward language acquisition.

Appropriate precautions were taken to minimize researcher bias via journaling throughout the data collection and analysis process. However, full disclosure necessitates revealing that the primary researcher has herself traveled with San José State University's study abroad program during the summer of 2010. Proper care was taken to avoid 
introducing any bias originating from her experiences with the program. This wideranging experience, however, also facilitated an "insider mindset", resulting in greater knowledge and understanding in regards to the attitudes and experiences of the student travelers.

\section{Conclusions}

This exploratory study sought insight into how travel motivations intertwine with the role of the local language (and discourse) involving the hosts and the affect on the tourism experience. One of the main focuses of the research was the desire on the tourist's part to experience cultural authenticity and the manner in which the difference in spoken language affects this experience of the tourists. This research incorporates the field of sociolinguistics, which studies the effect of society on language (and vice versa), in addition to the theory of tourism, as proposed by Fox (2008) in her article on the role of English in tourism. In this study, however, the concept is extended to study the role that languages in general, as well as the difference in native languages of guests and hosts, play in shaping the tourism discourse thereby influencing tourists' experience of a destination.

Findings of the study indicate that the language at a destination as well as discourse involving the hosts interact in complex ways with travel motivations of the student tourists and their quest for cultural authenticity. This is certainly affected by the length of their stay at the destination. The subjective nature of cultural authenticity lends itself to formation of individualistic and unique definitions and perceptions in the minds of tourists. However, language is found to be a running theme and is intricately related to 
the perception of culture in all the cases.

The role of language in shaping the experience of a tourist, in this case, a student traveler, is significant. It also affects and is in turn affected by the interaction with the host population (and with other international travelers), which is a highly desirable component of cultural authenticity as the findings of this study indicate. Theoretical model 1 provides the framework for explaining this phenomenon.

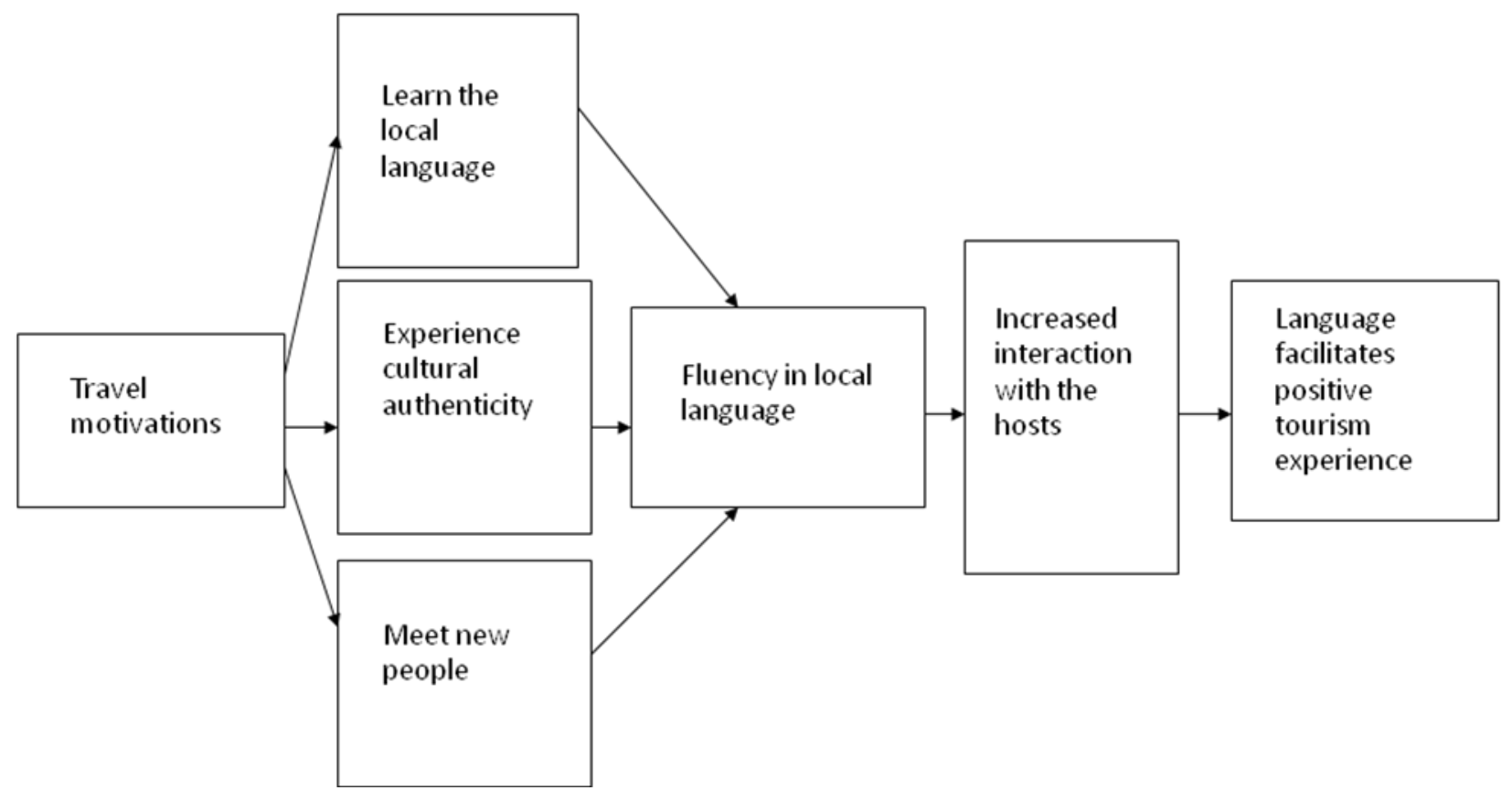

Figure 1

\section{Theoretical model 1}

The student travelers that were more concerned with cultural experiences and subjective negotiations of meanings than actual objects and places were able to use their language skills to achieve their goals. Since in these cases there was a huge focus on experiences with other people in the host country, fluency in the local language was certainly regarded as a huge advantage. It aided the student travelers in reaching out to 
others and gave them the freedom to create their own experiences, resulting in more positive experiences. It also made them less limited and more independent in terms of being on their own in the foreign country as they were more comfortable in approaching strangers, armed with the knowledge of the local language.

In contrast, student travelers that lacked fluency in the local language found it increasingly difficult to break away from their friends and mingle with the locals, or make new friends at the destination. Theoretical model 2 provides the framework for explaining this phenomenon.

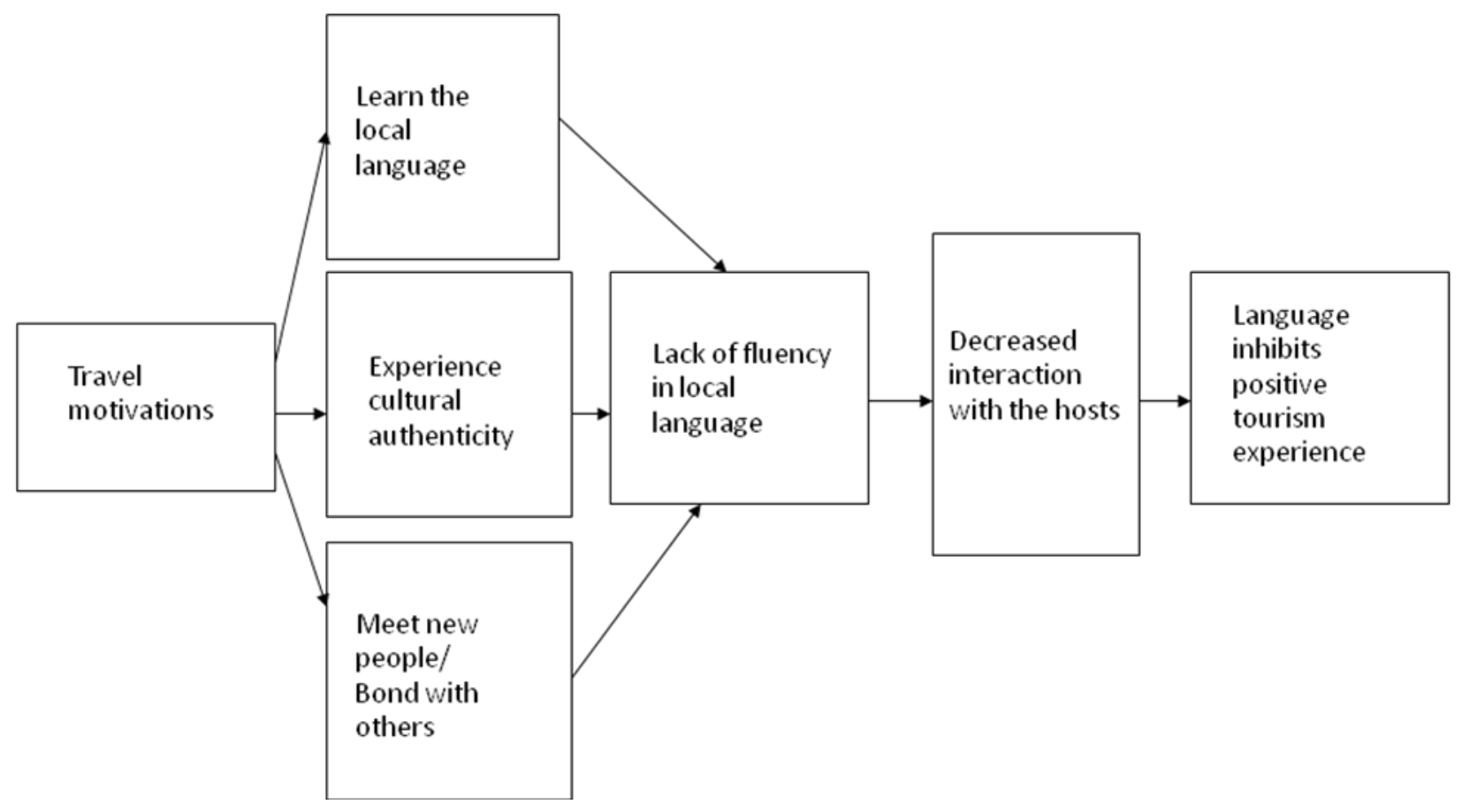

Figure 2

\section{Theoretical model 2}

The lack of fluency in the local language interfered hugely with the level of interaction the student-travelers desired with the local population. The quality of their 
experiences was greatly reduced by the lack of opportunity to freely interact with the host population. There were more negative experiences, involving feelings of frustration and isolation, expressed by student-travelers in these cases.

Recommendations. In this study, we explored the complex ways in which travel and quest for cultural authenticity intertwine with language and interaction with the hosts. Results from this exploratory study prompt several recommendations for serviceproviders in the tourism industry as well as for tourism researchers. The recommendations are also for study-abroad programs and other tour operators, urging them to facilitate awareness and preparedness for travelers in order to help them get the most out of their travel experience. The research findings suggest that being mindful of the culture of a country being visited, and of its spoken language, can help the travelers prepare better for their trip. Having made the choice to visit a destination, spending time and effort on acquiring host language skills can be very useful in a foreign country. Even when travel is undertaken for a short duration, interactions at places that tourists frequent are part of the overall travel experience. Whether or not use of the local language enhances that experience depends on the expectations of the tourists. However, surveys done at the destinations can be designed to elicit information on the familiarity that the tourists have with the local language and their overall experience. These details can be the preliminary information used to indicate connections between language skills and tourism experience.

English is a universally accepted common world language and enjoys its place as the most widely spoken language in the world. Various countries, however, have their 
own spoken language and take pride in it. With the increase in homogeneity of language where everybody can speak English, the less popular, more local languages are constantly disappearing from the society. Not only is an interest in a place's local language a mark of respect for that culture, enhancing the experience of interaction with the local population, it also elevates the status of the local language and keeps it alive.

Since tourism is a service industry, and one of the biggest economic sectors in many countries, in order to cater to the tourists, most places train their tour guides and other service providers to speak the language of the most frequent and largest group of visitors to the place. However, in order to provide a richer cultural experience, service providers could possibly focus on facilitating opportunities for tourists, especially the ones traveling for a longer duration, to engage in conversations with the locals in the local language.

The recommendations also include a plea to travel and tourism researchers to pay more attention to the place of language in the context of tourism, especially in the international domain, since it is clearly plays a huge role in shaping tourist experiences.

Areas for future research. Since this exploratory study focused on native speakers of English and student travelers who traveled with the San Jose State University study-abroad program, future research should cover a broader spectrum of tourists. While the sample should be homogenous, it could be a different segment of tourists, such as backpackers, business travelers that spend more than a week in a place, or even professionals visiting foreign countries for purposes of long-term projects, in which case they do not usually stay in hotels but live in apartments or other dwellings for a few 
months. The sample could further involve native speakers of another language (not English), which would add another dimension to the research. Since English is the most commonly spoken language around the world, it would still play a huge role in the ability of the tourists and the locals to find a common language for interaction. However, the native language of the tourist and that of the host would possibly change the meaningmaking and other variables of the discourse, and would be worth exploring.

Language could be something a tourist does no pay close attention to until s/he is in a situation that forces him/her to acknowledge the significance of knowing the local language. There could also be instances where the spoken language is similar but the difference in the culture adds another layer to the created as well as inferred meanings. This also makes for a potentially promising area for research regarding the interplay between language and tourist experience. Questions that could be further explored are: (a) How does difference in culture influence communication even when the spoken language is the same? (b) How do mass tourists negotiate meanings and experience a place with their interaction with the host population limited to that with service providers who may speak their language? (c) How do backpackers experience a place with limited knowledge of the local language? (d) How do international experiences involving a different language at the destination change future travel motivations for the tourists? (e) How does the effect of the difference in spoken language at the destination on the tourism experience change the attitudes of an individual upon return? (f) What is the host population's perception of tourists that try to step outside their comfort zone and try to communicate in the host language? 
Language and tourism are both intensively people oriented domains, and are an integral part of modern day society. Tourism is replete with opportunity for multicultural and multilingual experiences that could be greatly affected by the tourism discourse and can be shaped by focusing on the interplay between tourism and language. Further interdisciplinary research addressing these two disciplines is not only useful but is also a promising area that needs much more attention than it has been warranted in the past. 


\section{References}

Abram, D. (1997). The spell of the sensuous: Perception and language in a more-than human world. New York: Vintage.

Basala, S. L. \& Klenosky, D. B. (2001). Travel-style preferences for visiting a novel destination: A conjoint investigation across the novelty-familiarity continuum. Journal of Travel Research, 40, 172-182.

Billinge, M. (1977) In search of negativism: Phenomenology and historical geography. Journal of Historical Geography, 3 (1), 55-67.

Bonn, M. A., Joseph, S. M. \& Dai, M. (2005). International versus domestic visitors: An examination of destination image perceptions. Journal of Travel Research, 43, 294-301.

Boorstin, D. (1964). The image: A guide to pseudo-events in America. New York: Harper.

Bruner, E.M. (1994) Abraham Lincoln as authentic reproduction: A critique of postmodernism. American Anthropologist, 96 (2), 397-415.

Bryce, D. (2007). Repackaging orientalism: Discourses on Egypt and Turkey in British outbound tourism. Tourist Studies, 7 (2), 165-191.

Byram, M. (1997). Teaching and assessing intercultural communicative competence. Clevedon: Multilingual Matters.

Chhabra, D. (2008) Positioning museums on an authenticity continuum. Annals of Tourism Research, 35 (2), 117-127.

Cohen, E. (1972). Towards a sociology of international tourism. Social Research, 39 (1): 164-189.

Cohen, E. (1979). A phenomenology of tourist types. Sociology, 13, 179-201.

Cohen, E. \& Cooper, R. I. (1985). Language and tourism. Annals of Tourism Research, 13 (4), 533-563.

Creswell, J. W. (2007). Qualitative inquiry and research design: Choosing among five approaches. Thousand Oaks, London and New Delhi: Sage.

Crik, M. (1996). Representations of international tourism in the social sciences: Sun, sex, sights, savings, and servility. In Y. Apostolopoulos (ed.). The sociology of tourism (pp. 15-50). London and New York: Routelage. 
Cronin, M. (2000). Across the lines: Travel, language, translation. Cork: Cork University Press.

Dann, G. (1977). Anomie, ego-enhancement, and tourism. Annals of Tourism Research, 4 (4), 184-194.

Dann, G. (2004). (Mis)representing the other in the language of tourism. Journal of Eastern Caribbean Studies, 29 (2), 76-94.

de Certeau, M. (1984) The practice of everyday life. Los Angeles and London: University of California Press.

Denzin, N. (1991) Images of postmodern society: Social theory and contemporary cinema. London: Sage.

Dunn Ross, E. \& Iso-Ahola, S. (1991). Sightseeing tourists' motivations and satisfaction. Annals of Tourism Research, 18 (2), 226-237.

Echtner, C. M. and Jamal, T. B. (1997). The disciplinary dilemma of tourism studies. Annals of Tourism Research, 24 (4), 868-883.

Elliott, J. (2005). Using narrative in social research. London: Sage Publications.

Fawcett, C. \& Cormack, P. (2001). Guarding authenticity at literary tourism sites. Annals of Tourism Research, 28, 686-704.

Fox, R. (2008). English in tourism: A sociolinguistic perspective. Tourism and Hospitality Management, 14 (1), 13-22.

Gottlieb, A. (1982). American's vacations. Annals of Tourism Research, 9, 165-87.

Gnoth, J. (1997). Tourism motivation and expectation formation. Annals of Tourism Research, 24 (2), 283-304.

Hollinshead, K. (2002) Playing with the past: Heritage tourism under the tyrannies of postmodern discourse. In The tourist experience, C. Ryan (ed.) (pp. 172-200). London: Continuum.

Hsu, C. H. C., Cai, L. A. and Li, M. (2010). Expectation, motivation, and attitude: A tourist behavioral model. Journal of Travel Research, 49 (3), 282-296.

Jaworski, A. and Pritchard, A. (eds) (2005) Discourse, Communication and Tourism. Clevedon: Channel View Publications. 
Jurowski, C. A. (2007). Tourism and intercultural exchange. Annals of Tourism Research, 34 (2), 551-552.

Kalinowski, K.M. (1992) Special Interest Tourism (pp. 27-36). Belhaven Press, London. Li, Y. (2000). Geographical consciousness and tourism experience. Annals of Tourism Research, 27 (4), 863-883.

MacCannell, D. (1973). Staged authenticity: Arrangements of social space in tourist settings. American Journal of Sociology, 79 (3), 589-603.

Mannell, R., and Iso-Ahola, S. (1987). Psychological nature of leisure and tourism experience. Annals of Tourism Research, 14, 314-331.

Mayo, E.J. \& Jarvis, L.P. (1981). The psychology of leisure travel: Effective marketing and selling of travel services. Boston: CBI publishing company.

McCabe, S. (2005) Who is a tourist: A critical review. Tourist Studies, 5 (1), 85-106.

McCabe, S. and E. H. Stokoe (2004). Place and Identity in Tourist Accounts. Annals of Tourism Research 31 (3), 601-22.

Mkono, M. (2012). Authenticity does matter. Annals of Tourism Research, 39 (1), 480483.

Oppermann, M. (1995). Travel life cycle. Annals of Tourism Research, 22 (3), 535-552.

Pearce, P.L. (1993). Fundamentals of tourist motivation. In D.G. Pearce, \& R.W. Butlet (Eds.). Tourism Research: Critiques and challenges (pp. 113-134). London: Routledge.

Pearce, P., and Lee, U. (2005). Developing the travel career approach to tourist motivation. Journal of Travel Research, 43 (3), 226-237.

Phipps, A (2006). Learning the arts of linguistic survival: Languaging, tourism, life. Clevedon: Channelview Publications.

Plog, S. (1974) Why destination areas rise and fall in popularity. The Cornell Hotel and Restaurant Administration Quarterly, 14 (3), 55-58.

Reisinger, Y. (1994) Tourist-host contact as a part of cultural tourism. World Leisure and Recreation, 36 (Summer), 24-28.

Reisinger, Y. \& Steiner, C. J. (2006). Reconceptualizing object authenticity. 
Annals of Tourism Research, 33 (1), 65-86.

Ryan, C. (1997). The chase of a dream, the end of a play. In The tourist experience: A new introduction, (ed.) (pp. 1-24). London: Cassell.

Salazar, N. B. (2006) Touristifying Tanzania: Local guides, global discourse. Annals of Tourism Research, 33 (3), 833-852.

Selwyn, T. (ed.) (1996). The tourist image: Myths and myth making in tourism. Chichester: John Wiley.

Smith, V. (ed.) (1989). Hosts and guests: The anthropology of tourism ( $2^{\text {nd }}$ edition). Philadelphia: Pennsylvania University Press.

Steiner, C.J. \& Reisinger, Y. (2006). Understanding existential authenticity. Annals of Tourism Research, 33 (2), 299-318.

Taylor, J. P. (2001). Authenticity and sincerity in tourism. Annals of Tourism Research, 28 (1), 7-26.

Thurlow, C. and Jaworski, A. (2003). Communicating a global reach: Inflight magazines as a globalising genre in tourism. Journal of Sociolinguistics, 7, 581-608.

Timothy, D.J. and Boyd, S.W. (2003) Heritage Tourism. Harlow: Prentice Hall.

Tuan, Y. (1977). Space and place: The perspective of experience. Minneapolis: University of Minnesota Press.

Tuan, Y. (1989). Surface phenomena and aesthetic experience. Annals of Association of American Geographers, 79 (2), 233-241.

Tuan, Y. (1993). Passing strange and wonderful: Aesthetics, nature, and culture. Island Press: Washington DC.

Uriely, N. (2005). The tourist experience: Conceptual developments. Annals of Tourism Research, 32 (1), 199-216.

Wang, N. (1999). Rethinking authenticity in tourism experience. Annals of Tourism Research, 26 (2), 349-370.

Weaver, P.A., Weber, K. \& McCleary, K.W. (2007). Destination evaluation: The role of previous travel experience and trip characteristics. Journal of Travel Research, 45 (3), 333-344. 
Woolard, K. (1998). Language ideology as a field of inquiry. In B.B. Schieffelin, K. Woolard and P.V. Kroskrity (eds) Language ideologies: Practice and theory (pp. 3-47). New York: Oxford University Press. 


\section{Appendix A}

\section{Interview Questions}

1. What made you decide to travel abroad as part of this program?

2. When you think of culture, what comprises a place's culture for you? What are its basic components, and what place does language possess in this context?

3. Can you please talk about your tourism experiences in (country name)?

4. Can you please talk about the times when you were aware of language differences and what were some of your experiences at that time?

Probes: Can you please talk about the times when language presented a challenge?

Can you tell me about the times when language enhanced your experience?

5. Please talk about your interactions with the host community (residents of the destination vs. service providers)? (If they are staying with the hosts, they would be encouraged to talk more about it and also to relate past experiences or future preferences based on those experiences in similar settings).

Probes: Describe any memorable episodes that affected your experience favorably?

Describe any unfavorable incidents with the hosts (for example episodes of miscommunication).

6. Was the level of interaction you desired with the locals affected by your knowledge or lack of the host language? How comfortable are you with cultures/people who speak a language different than English?

7. How do you make sure you maintain the level of interaction with the local population (residents, not service providers) you desire? If you do not desire much interaction, what steps do you take to ensure you do not have to interact much with the locals?

8. What was your interaction with other students, local or international like? 
9. Please share the kind of preparations that you did related to studying the host country's language before traveling overseas.

10. Please share your educational experience with us. Please relate how the difference in the spoken language affected your educational experience. 


\section{Appendix B}

\section{Informed Consent Form}

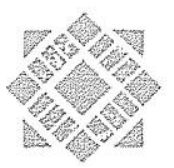

\section{San José State} UNIVERSITY

College of Applied Sciences and Arts Department of Hospitality, Recreation \& Tourism Management

One Washington Square San Jose, CA 95192-0211 Voice: 408-924-3000
The California State University: Chancellor's Office Dominguez Hillts, Frostands, Chico Hayward, Humboldt, Long Beach, Los Angeles, Maritime Academy, Monterey Bay, Northridge. Pomona San Francisco, San Jase, San Luis Olispo, San Marcos, Sonoma, Slanislaus

\section{Agreement to Participate in Research}

Responsible Investigator(s): Avina Ramnani, Graduate Student Title of Protocol: The role that language plays in the international cultural tourism experience

1. You have been asked to participate in a research study investigating the role that language (language barrier or knowledge of a destination's host language) plays in shaping the tourism experience.

2. You will be asked to share your tourism experience that included cultural components, to an international destination, in an interview with the researcher. Your responses will be audio recorded. Notes will also be taken during the interview by the researcher.

3. There are no anticipated physical or psychological risks in this study.

4. Your participation in this study will yield data that upon analysis might lead to more research to explore the significance of the native language of a host nation in terms of its tourism potential, and may have important connotations for the field of linguistics.

5. Although the results of this study may be published, no information that could identify you will be included. The written report will include pseudonyms chosen by you, and will not identify you directly.

6. There is no compensation for participation in this study

7. Questions about this research may be addressed to Avina Ramnani (avina.ramnani@gmail.com, (408) 876 0327. Complaints about the research may be presented to Dr. Randy Virden, Ph.D. Department Chair, Hospitality, Recreation, and Tourism Management, College of Applied Sciences and Arts, San Jose State University, (408) 924 3199. Questions about a research subjects' rights, or research-related injury may be presented to Pamela Stacks, Ph.D. Associate Vice President, Graduate Studies and Research, at (408) 924-2427.

8. No service of any kind, to which you are otherwise entitled, will be lost or jeopardized if you choose not to participate in the study.

9. Your consent is being given voluntarily. You may refuse to participate in the entire study or in any part of the study. You have the right to not answer any interview questions you do not wish to answer. If you decide to participate in the study, you are free to withdraw at any time without any negative effect on your relations with San Jose State University.

10. At the time that you sign this consent form, you will receive a copy of it for your records, signed and dated by the investigator.

The signature of a subject on this document indicates agreement to participate in the study.

The signature of a researcher on this document indicates agreement to include the above named subject in the research and attestation that the subject has been fully informed of his or her rights.

Participant's Signature Date

Investigator's Signature Date 


\section{Appendix C}

\section{Informed Consent Form}

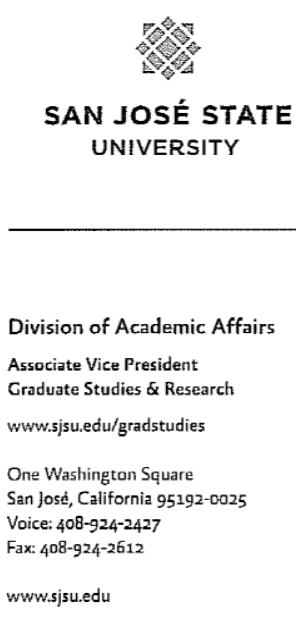

To: Avina Ramnani

From: Pamela Stacks, Ph.D.

Associate Vice President

Graduate Studies and Research

Date: June 25, 2010

The Human Subjects-Institutional Review Board has approved your request to use human subjects in the study entitled:

"The role that language plays in international cultural tourist experience"

This approval is contingent upon the subjects participating in your research project being appropriately protected from risk. This includes the protection of the anonymity of the subjects' identity when they participate in your research project, and with regard to all data that may be collected from the subjects. The approval includes continued monitoring of your research by the Board to assure that the subjects are being adequately and properly protected from such risks. If at any time a subject becomes injured or complains of injury, you must notify Dr. Pamela Stacks, Ph.D. immediately. Injury includes but is not limited to bodily harm, psychological trauma, and release of potentially damaging personal information. This approval for the human subject's portion of your project is in effect for one year, and data collection beyond June 25, 2011 requires an extension request.

Please also be advised that all subjects need to be fully informed and aware that their participation in your research project is voluntary, and that he or she may withdraw from the project at any time. Further, a subject's participation, refusal to participate, or withdrawal will not affect any services that the subject is receiving or will receive at the institution in which the research is being conducted.

If you have any questions, please contact me at (408) 924-2427.

Protocol \#S1002200

cc: Randy Virden 0211 